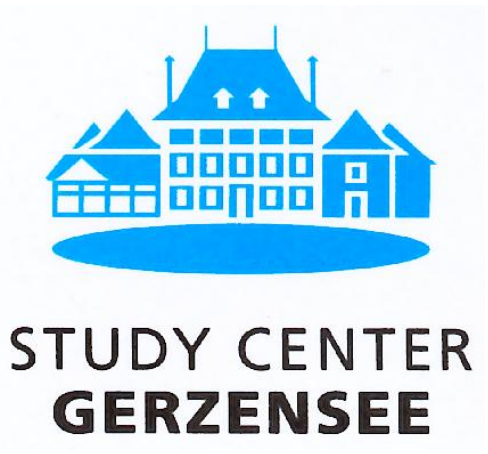

\title{
Fiscal Federalism, Taxation and Grants
}

\author{
Martín Gonzalez-Eiras and Dirk Niepelt
}

Working Paper 16.05

This discussion paper series represents research work-in-progress and is distributed with the intention to foster discussion. The views herein solely represent those of the authors. No research paper in this series implies agreement by the Study Center Gerzensee and the Swiss National Bank, nor does it imply the policy views, nor potential policy of those institutions. 


\title{
Fiscal Federalism, Taxation and Grants*
}

\author{
Martín Gonzalez-Eiras ${ }^{\dagger} \quad$ Dirk Niepelt ${ }^{\ddagger}$
}

August 17, 2016

\begin{abstract}
We propose a theory of tax centralization and inter governmental grants in politico-economic equilibrium. The cost of taxation differs across levels of government because voters internalize general equilibrium effects at the central but not at the local level. This renders the degree of tax centralization and the tax burden determinate even if none of the traditional, expenditure-related motives for centralization considered in the fiscal federalism literature is present. If central and local spending are complements and the trade-off between the cost of taxation and the benefit of spending is perceived differently across levels of government, inter governmental grants become relevant. Calibrated to U.S. data, our model helps to explain the introduction of federal grants at the time of the New Deal, and their increase up to the turn of the twenty-first century. Grants are predicted to increase to approximately $5.5 \%$ of GDP by 2060 .
\end{abstract}

JEL Classification: D72, E62, H41, H77

Keywords: Fiscal policy, Federalism, Politico-economic equilibrium, Markov equilibrium, Public goods, Grants, Political Economy

\section{Introduction}

Whether control over fiscal policy decisions should rest with central, regional or local governments depends on how these governments make use of their authority. A broad body of fiscal federalism literature has emphasized that depending on the policy task, the efficiency of policy choices may differ across levels of government. It has argued, therefore, that certain decisions are best taken de-centrally to minimize informational or other frictions which render it difficult to cater to heterogeneous needs, while others

\footnotetext{
*For useful comments and discussions, we thank Asger Lau Andersen, Maximilian von Ehrlich, David Dreyer Lassen and seminar participants at CEMFI, IIBEO workshop, and Universidad Carlos III.

${ }^{\dagger}$ University of Copenhagen. Oster Farimagsgade 5, 1353 Copenhagen K, Denmark. E-mail: mge@alum.mit.edu

†Study Center Gerzensee and University of Bern. P.O. Box 21, CH-3115 Gerzensee, Switzerland. E-mail: dirk.niepelt@szgerzensee.ch.
} 
should best be taken centrally to ensure that all important consequences of policy are internalized.

These results have been derived with a nearly exclusive focus on government spending. That the efficiency of tax collections might also differ across levels of government has attracted much less attention although it appears equally relevant. By abstracting from differences in funding efficiency the fiscal federalism literature has abstracted from an important motive for decoupling revenue collection and spending across levels of government. In fact, it has typically ruled out such decoupling by assuming - counterfactually - that governments individually balance their budgets. ${ }^{1}$

In this paper, we take issue with the implicit assumption in much of the literature that the social cost of taxation is identical across levels of government. We argue that there are reasons to expect the opposite and explore the implications. Most importantly, we show that if certain levels of government are in a better position to tax then this can determine the equilibrium degree of centralization of tax collections. And if, in addition, other levels of government are in a better position to spend-as argued by the fiscal federalism literature - then this provides a straightforward explanation for the presence of intergovernmental transfers or grants. The specific source of cost differences we focus on is inherently dynamic ${ }^{2}$ and its implications appear consistent with the data.

The model features a central, or federal, government and many regional governments that impose labor income taxes to finance the provision of public services. ${ }^{3}$ Taxation slows down capital accumulation and thus has general equilibrium effects: It drives up interest rates and lowers future wages which reduces the tax base in the subsequent period. Policy makers and voters at the federal level-rationally - internalize these general equilibrium effects to the extent that they are of relevance for current voters. ${ }^{4}$ In contrast, policy makers and voters at the regional level-rationally - do not perceive general equilibrium effects of their decisions since regions are small relative to the nation and markets are not segmented. As a consequence, the net cost of a federal tax hike as perceived by a voter participating in national elections differs from the net cost of a regional tax hike as perceived in local elections.

Against this background, we pursue the positive questions of which level of government taxes more or less, why inter governmental grants exist, and why they have risen in prominence. Our positive analysis in the context of a dynamic model of politico-economic equilibrium contrasts with the normative approach adopted in much of the fiscal federalism literature. While the latter typically identifies the welfare maximizing exclusive assignment of control to either the federal government or regional governments, we allow both levels of government to tax and spend and solve for the politico-economic equilibrium

\footnotetext{
${ }^{1}$ The balanced budget assumption also is unrealistic because of "inter temporal decoupling," namely budget deficits or surpluses.

${ }^{2}$ Another obvious source relates to increasing returns in tax collections. Yet another one relates to negative externalities of taxation; see below for a discussion of the literature on tax competition.

${ }^{3}$ We refer to a state with a multi-tier political organization as a "federal" state, and to a government that makes decisions at the central level as a "federal" government. We refer to goverments making decisions at the local level as "regional" governments.

${ }^{4}$ The welfare consequences for yet unborn cohorts who are not represented in the political process are not internalized.
} 
with grants in a standard macroeconomic framework. ${ }^{5}$

In the model, the quantity or quality of public services depends on spending at the federal and regional levels. We first consider a specification where federal and regional spending are perfect substitutes and all traditional fiscal federalism considerations are absent: Government spending does not generate externalities and preferences for public services are uniform across the population. In such an environment, the equilibrium degree of centralization is indeterminate if the economy is static. But in the dynamic economy we consider, differential net costs of taxation render the equilibrium composition of tax collections across levels of government determinate. Grants are irrelevant because spending at the federal and regional level are perfect substitutes.

Next, we introduce elements emphasized in the fiscal federalism literature. Heterogeneous preferences for public services and a restriction for the federal government to distribute resources uniformly give rise to a motive to "top up" taxes in regions with high spending needs. Cross-regional externalities from public service provision increase or decrease federal spending depending on whether the externalities are positive or negative, but they do not affect the trade-off governing regional policy choices. In a framework with exclusive control over fiscal policy, externalities of either sign would favor centralization from a welfare point of view. In our framework the federal government cannot prevent spending at the regional level; all it can do is to abstain from raising taxes and from spending. ${ }^{6}$

Finally, we relax the assumption that regional and federal government spending are perfect substitutes. With complementarities, the federal government is handicapped in its ability to affect the provision of public services because regional spending is essential. This renders useful the ability to employ federal grants to increase regional spending. When tax revenue at the federal level is "cheap," grants allow to channel that revenue into the most productive use (regional, not only federal spending). And when externalities from public service provision are positive, grants allow to increase spending above the level that regional governments would choose in the absence of such grants. In equilibrium, the degree of centralization of both taxes and spending is determinate and as a consequence, the size of intergovernmental grants is uniquely determined as well. Grants crowd out local taxation, in line with recent empirical evidence. ${ }^{7}$

While our main results are derived under the assumption that governments resort to labor income taxation we also consider the case of capital income taxes. In contrast to the former, capital income taxes do not affect capital accumulation once they are politically chosen. From the perspective of federal and regional voters, the net costs of taxation thus are the same. With perfect substitutability of government spending, traditional fiscal federalism considerations completely determine equilibrium centralization. With

\footnotetext{
${ }^{5}$ Of course, the mechanisms we emphasize would also be present in a model that adopts a normative perspective.

${ }^{6}$ When externalities are negative, society would be better off if regional governments lowered spending but this is not incentive compatible.

${ }^{7}$ For example, Knight (2002) finds statistically and economically significant crowding out. He addresses identification problems (an omitted variable bias due to the positive correlation between grant levels and unobserved preferences for public spending) by using the political power of state congressional delegations as instruments.
} 
less than perfect substitutability, grants are present when positive spending externalities outweigh deadweight costs associated with the transfers. We also check whether the type of grant-uniform or matching - makes a difference. We find that for the most part, it does not.

The model sheds light on the transformation of the fiscal system in the United States at the time of the Great Depression and the New Deal. ${ }^{8}$ Before 1933, all governments mainly resorted to tariffs and property taxes. After 1940, all but especially the federal government, dominantly relied on income taxes, and total tax collections increased. Also around 1940, federal grants rose in prominence, increasing from virtually zero in 1933 to $9.4 \%$ of national expenditures in $1940 .{ }^{9}$ The model can rationalize this emergence of grants in parallel to the change of tax base and the rise of taxation under the assumption that tariffs and property taxes have a weaker effect on savings decisions than labor income taxes.

In simulations, the model also captures the rise in the size of grants until the early twenty first century. ${ }^{10}$ Furthermore, it predicts grants to continue to increase up to approximately $5.5 \%$ of GDP by 2060 . In a counterfactual analysis we find that if general equilibrium effects of taxation were not internalized at the federal level, federal taxes would be six percentage points lower in the year 2000, regional taxes four percentage points higher, and grants would not be employed.

Related Literature We build on the classic analysis of fiscal federalism that features a trade-off between forces favoring centralization and decentralization. Oates (1972) emphasizes externalities in the provision of public goods on the one hand, and heterogeneity of preferences across regions on the other. He finds that absent spillovers and cost-savings from centralized provision, decentralization is preferable to uniform provision. But without information frictions, nothing prevents differentiated provision of services even in a centralized system (Oates, 1999).

Similar arguments are discussed in the theoretical political science literature (e.g., Kincaid, 2011). A federalist governance structure allowing for multiple centers of power is considered best suited for diverse countries, in particular if diversity is geographically based. Treisman (2007) critically discusses the rationales for and against political decentralization. He argues that administrative efficiency only requires administrative, not political decentralization and he questions the argument that local governments generally are better able or motivated to extract local information. ${ }^{11}$ Our argument is related as it stresses the possible decoupling of tax and spending decisions.

The literature subsequent to Oates (1972) has offered various explanations based on political economy frictions for the uniformity of centralized policy choices. For example, legislative bargaining among regional representatives at the federal level may imply

\footnotetext{
${ }^{8}$ See Wallis (2000) for a discussion of fiscal arrangements in U.S. history.

${ }^{9}$ See Wallis $(2000)$.

${ }^{10}$ Grants increased, with marked fluctuations, up to $3 \%$ of GDP in the aftermath of the Great Recession.

${ }^{11}$ Treisman (2007) suggests that the most convincing arguments for the relevance of decentralization are that it tends to increase policy stability and to lead to failures of fiscal coordination. See the discussion on tax competition below.
} 
reduced sensitivity of policy to regional needs (Lockwood, 2002); differentiated central service provision can give rise to costly bargaining and delay and may thus be avoided (Harstad, 2007); ${ }^{12}$ credibility problems in signaling local tastes to the central government may generate inefficient federal policy choices (Kessler, 2014); and centralization may increase accountability but must be accompanied by policy uniformity because otherwise, the central government would implement policies favoring regions that monitor more extensively (Boffa, Piolatto and Ponzetto, 2016). ${ }^{13}$ Alesina and Spolaore (1997) analyze the effect of international integration on the costs and benefits of centralization and thus, the number of countries. ${ }^{14}$

Wallis (2000) documents that the United States passed through distinct systems of government finance and suggests that federal, state and local governments may face differential costs to raise revenues from specific sources. Our model provides an explanation for such cost differences based on the general equilibrium effects of taxation, and it can rationalize the change of regime during the 1930s. The notion of differential costs of taxation due to the internalization or not of general equilibrium effects relates to Soares (2005) and Gonzalez-Eiras and Niepelt (2008) where the political support for education or social-security financing, respectively, depends on such effects as well. ${ }^{15}$

Our work also relates to the literature on tax competition (e.g., Gordon, 1983) which points out that uncoordinated local taxation of mobile factors gives rise to revenue (and other) externalities across regions. A federal government concerned with welfare at the national level may correct these externalities by imposing federal taxes or transferring resources to regional governments through grants, among others. Our paper shares the focus on general equilibrium effects of taxation but its perspective is positive rather than normative. We emphasize that different perceptions about the cost of taxation at the federal and the regional level give rise to a positive theory of fiscal federalism and may explain federal grants.

Uniform federal grants combined with non-uniform federal taxes (or vice versa) redistribute between regions and may constitute a form of inter-regional risk sharing (see, for example, Persson and Tabellini, 1996). The fact that such risk-sharing is very common does not provide a rationale for federal grants, however, since risk sharing in the joint interest of regions can be implemented without federal intervention. In our model, fiscal policy does not redistribute, and grants are used to achieve an allocation of resources that regions would not choose by themselves. ${ }^{16}$

On the methodological side, our paper relates to the literature on dynamic politicoeconomic equilibrium (Krusell, Quadrini and Ríos-Rull, 1997). While most work in this literature studies equilibria with a single political decision maker Song, Storesletten and

\footnotetext{
${ }^{12}$ See also Besley and Coate (2003).

${ }^{13}$ Related, Seabright (1996) argues that centralization limits the control rights of voters.

${ }^{14}$ See also Bolton and Roland (1997).

${ }^{15}$ See also Kotlikoff and Rosenthal (1990).

${ }^{16}$ Since we are interested in explaining long run trends in U.S. fiscal policy, risk sharing considerations are of second order. Furthermore, the absence of fiscal equalization is a natural assumption as the U.S. federal government does not use grants for this purpose. An exception is the joint financing of social insurance and welfare programs since the federal share of those costs increases as state income falls. See Gruber (2011, page 266).
} 
Zilibotti (2012) analyze politico-economic equilibrium in a setting with a continuum of governments that take factor prices as given. We solve a dynamic game with a continuum of regional governments and a central government that internalizes general equilibrium effects.

Outline The remainder of the paper is structured as follows. In section 2, we describe the model and in section 3, we define equilibrium. Sections 4 and 5 contain the main analysis and extensions, respectively. In section 6 , we discuss quantitative implications of the model and contrast them with empirical evidence. Section 7 concludes.

\section{The Model}

\subsection{Demographics and Institutions}

We consider an economy inhabited by overlapping generations: workers and retirees. Workers supply labor, pay taxes, consume and save. In the subsequent period, they retire, consume the return on their savings, and die. The ratio of workers to retirees in period $t$ equals $\nu_{t}$.

The economy is composed of a continuum of regions of measure one over the unit interval. Each region is populated by a continuum of agents. The mass of agents and their age profile is identical across regions but the preferences of agents for publicly provided services may vary. Formally, regions are indexed by $i$ and partitioned into $J$ groups with groups indexed by $j$. All agents in all regions in group $j$ share the parameter $\gamma_{t}^{j}$ in their preference for publicly provided services. The mass of regions in group $j$ is given by $\theta_{t}^{j}$, and in every period $\sum_{j=1}^{J} \theta_{t}^{j}=1$. The demographic, preference parameters, as well as their cross-regional distribution follow deterministic processes.

Policy decisions are taken by governments at the federal and the regional level. Federal and regional governments act in the interest of voters participating in nationwide and regional elections, respectively. None of the governments can commit, and in each period they take decisions simultaneously.

\subsection{Production of Final Good}

A continuum of competitive firms transforms capital and labor into output. Capital is owned by retirees - it corresponds to the savings of workers in the preceding period - and fully depreciates after a period. The economy-wide capital stock per worker, $k_{t}$, therefore corresponds to the economy-wide per-capita savings of workers in the previous period, $s_{t-1}$, normalized by $\nu_{t}$. Labor is supplied inelastically. The gross interest rate $R_{t}$ and the wage $w_{t}$ are determined competitively.

We assume that the production function displays constant returns to scale such that factor prices in period $t$ only depend on $k_{t}$,

$$
R_{t}=R\left(k_{t}\right), w_{t}=w\left(k_{t}\right) .
$$


Moreover, we assume that the elasticities of the factor prices with respect to the capitallabor ratio are independent of the latter, $\epsilon_{R k} \equiv \mathrm{d} \ln \left(R_{t}\right) / \mathrm{d} \ln \left(k_{t}\right) \perp k_{t}, \epsilon_{w k} \equiv \mathrm{d} \ln \left(w_{t}\right) / \mathrm{d} \ln \left(k_{t}\right) \perp k_{t}$. Examples of production functions that satisfiy these assumptions include the CobbDouglas production function with capital share $\alpha$ where factor prices equal $R_{t}=\alpha k_{t}^{\alpha-1}$ and $w_{t}=(1-\alpha) k_{t}^{\alpha}$, the $A k$ production function, or a small open economy with exogenous factor prices.

The independence assumption can be disposed of at the cost of loosing the ability to derive closed-form solutions.

\subsection{Production and Financing of Public Services}

The quantity or quality of publicly provided services (or public services, for short) in a region $i$ in group $j, g_{t}^{i j}$, depends on public spending at the regional level and nationwide. Let $e_{t}^{i j}$ denote spending at the regional level and $e_{t}$ spending by the federal government. Note that the latter occurs uniformly. ${ }^{17}$

We allow for positive or negative externalities across regions. Let $e_{t}^{j}$ denote spending in a typical region in group $j$ and let $\vec{e}_{t} \equiv\left(e_{t}^{1}, \ldots, e_{t}^{J}\right)$ denote the vector that collects regional spending across the $J$ typical regions. (Throughout the paper, we use this notation for cross sections.) Publicly provided services in region $i$ in group $j$ are a function of $\left(e_{t}^{i j}, \vec{e}_{t}, e_{t}\right)$. We specify this function as

$$
g_{t}^{i j}=a\left(e_{t}^{i j}, e_{t}\right) \times A\left(\vec{e}_{t}, e_{t}\right)^{\lambda} \forall i, j .
$$

The aggregator $a(\cdot)$ at the regional level and the cross-regional aggregator $A(\cdot)$ are increasing in all their arguments and the exponent $\lambda$ measures the strength of the externality. In subsequent sections, we will adopt simple - and mutually consistent-functional form assumptions for $a(\cdot)$ and $A(\cdot)$. In particular, we will first consider the case without externalities, $\lambda=0$, and with perfect substitutability between spending by the regional and federal governments, $a\left(e_{t}^{i j}, e_{t}\right)=e_{t}^{i j}+e_{t}$, before studying more general settings. ${ }^{18}$

Spending by the federal government is financed by a labor-income tax at rate $\tau_{t}$ and spending by region $i$ in group $j$ is financed by a tax at rate $\tau_{t}^{i j}$ as well as a uniform grant from the federal government, $x_{t}$. (See section 5 for a discussion of matching grants.) We allow for proportional deadweight losses of grants at rate $1-\sigma \geq 0$. Since all governments balance their budget in each period this implies

$$
e_{t}=w_{t}\left(\tau_{t}-x_{t}\right), \quad e_{t}^{i j}=w_{t}\left(\tau_{t}^{i j}+\sigma x_{t}\right), \quad e_{t}^{j}=w_{t}\left(\tau_{t}^{j}+\sigma x_{t}\right) \quad \forall i, j,
$$

where $\tau_{t}^{j}$ denotes the regional tax rate in a typical region in group $j$.

Tax rates and grants are non-negative.

\footnotetext{
${ }^{17}$ For rationalizations of policy uniformity at the federal level, see the literature review in the introduction.

${ }^{18}$ See the discussion below and appendix A for micro foundations of the general aggregator function we consider.
} 


\subsection{Preferences and Household Choices}

Workers and retirees in period $t$ value private consumption, $c_{1, t}$ and $c_{2, t}$ respectively, as well as public services. They discount the future at factor $\beta \in(0,1)$. For analytical tractability, we assume that period utility functions are logarithmic. Welfare of a worker in region $i$ in group $j$ who chooses savings $s_{t}^{i j}$ is given by

$$
\begin{array}{ll} 
& \ln \left(c_{1, t}^{i j}\right)+\gamma_{t}^{j} \ln \left(g_{t}^{i j}\right)+\beta\left(\ln \left(c_{2, t+1}^{i j^{\prime}}\right)+\mathbb{E}_{t}\left[\gamma_{t+1}^{j^{\prime}} \ln \left(g_{t+1}^{i j^{\prime}}\right)\right]\right) \\
\text { s.t. } & c_{1, t}^{i j}=w_{t}\left(1-\tau_{t}-\tau_{t}^{i j}\right)-s_{t}^{i j}, \quad c_{2, t+1}^{i j^{\prime}}=s_{t}^{i j} R_{t+1} .
\end{array}
$$

The expectation is taken with respect to the probability that region $i$ of type $j$ in period $t$ becomes a region of type $j^{\prime}$ in period $t+1$. To streamline notation, we define $\varphi_{t}^{i j} \equiv$ $\left(1-\tau_{t}-\tau_{t}^{i j}\right)$ and correspondingly, $\varphi_{t}^{j} \equiv\left(1-\tau_{t}-\tau_{t}^{j}\right)$.

Taking prices and taxes as given the worker optimally chooses

$$
s_{t}^{i j}=\frac{\beta}{1+\beta} w_{t} \varphi_{t}^{i j} .
$$

Conditional on prices, taxes and savings in the preceding period the welfare of a worker and a retiree, respectively, thus equal (dropping constants)

$$
\begin{aligned}
U_{t}^{i j, w} & =(1+\beta)\left(\ln \left(w_{t}\right)+\ln \left(\varphi_{t}^{i j}\right)\right)+\beta \ln \left(R_{t+1}\right)+\gamma_{t}^{j} \ln \left(g_{t}^{i j}\right)+\beta \mathbb{E}_{t}\left[\gamma_{t+1}^{j^{\prime}} \ln \left(g_{t+1}^{i j^{\prime}}\right)\right], \\
U_{t}^{i j, r} & =\ln \left(s_{t-1}^{i j^{\prime}}\right)+\ln \left(R_{t}\right)+\gamma_{t}^{j} \ln \left(g_{t}^{i j}\right),
\end{aligned}
$$

where we allow for the possibility that region $i$ of type $j$ in period $t$ was of type $j^{\prime}$ in period $t-1$. Welfare of a worker and a retiree in a typical region in group $j, U_{t}^{j, w}$ and $U_{t}^{j, r}$ respectively, are defined accordingly.

\subsection{Elections}

Elections take place at the beginning of each period, simultaneously in all regions and nationwide. Workers and retirees may vote on candidates whose electoral platforms specify values for the policy instruments as well as other characteristics like "ideology" that are orthogonal to the fundamental policy dimensions of interest. These other characteristics are permanent and cannot be credibly altered in the course of electoral competition. Moreover, their valuation differs across voters (even if voters agree about the preferred policy platform) and is subject to random aggregate shocks, realized after candidates have chosen their platforms. This "probabilistic-voting" setup renders the probability of winning a voter's support a continuous function of the competing policy platforms. It implies that equilibrium policy platforms smoothly respond to changes in the demographic structure and other fundamentals.

In the Nash equilibrium of the game with two competing candidates in a constituency choosing platforms to maximize their expected vote shares, both candidates propose the same policy platform. ${ }^{19}$ This platform maximizes a convex combination of the objective

\footnotetext{
${ }^{19}$ See Lindbeck and Weibull (1987) and Persson and Tabellini (2000) for discussions of probabilistic voting.
} 
functions of all groups of voters, where the weights reflect the groups' sizes and sensitivity of voting behavior to policy changes. Those groups that care the most about policy platforms rather than other candidate characteristics are the most likely to shift their support from one candidate to the other in response to small changes in the proposed platforms. In equilibrium, such groups of "swing voters" thus gain in political influence and tilt policy in their own favor. If all voters are equally responsive to changes in the policy platforms, electoral competition implements the utilitarian optimum with respect to voters. We assume that across groups of typical regions, voters are equally responsive to proposed changes in policy platforms. However, we allow for age related variation in responsiveness, reflected in a per capita political influence weight of unity for young voters and a per capita weight of $\omega \geq 0$ for retired voters.

\section{Equilibrium}

\subsection{Competitive Equilibrium}

We focus on symmetric equilibria where all regions within the same group behave identically, except possibly a set of regions of measure zero. The state is given by $z_{t}$, which includes the exogenous demographic and preference parameters as well as the endogenous state $\vec{s}_{t-1} \cdot{ }^{20}$ Conditional on $z_{t}$, the production function as well as competition among firms determine factor prices, $w_{t}$ and $R_{t}$. A financing policy $\left(\vec{\tau}_{t}, \tau_{t}, x_{t}\right)$ (or policy for short) then determines public services, $\vec{g}_{t}$, capital accumulation, $\vec{s}_{t}$, and thus $z_{t+1}$. Proceeding recursively, a policy sequence $\left\{\vec{\tau}_{s}, \tau_{s}, x_{s}\right\}_{s \geq t}$ fully determines an allocation and price system.

Definition 1. A competitive equilibrium conditional on $z_{0}$ and a policy sequence $\left\{\vec{\tau}_{t}, \tau_{t}, x_{t}\right\}_{t \geq 0}$ is given by an allocation and price system such that

i. capital evolves according to $k_{t}=s_{t-1} / \nu_{t}$, with $s_{t-1} \equiv \sum_{j=1}^{J} \theta_{t-1}^{j} s_{t-1}^{j}$, and factor prices are determined according to (1) for all $t$;

ii. the government budget constraints (2) and (3) are satisfied for all $t$; and

iii. households optimize: (4) is satisfied for all $i, j, t$.

\subsection{Politico-Economic Equilibrium}

In politico-economic equilibrium political decision makers optimally choose the values of the policy instruments under their control, taking all implications of their actions into account and forming rational expectations about future policy choices. We assume that these choices are Markov that is, they are functions of the fundamental state variables.

\footnotetext{
${ }^{20}$ In general, the state also includes the level of assets in each individual region. Logarithmic preferences imply that the capital stock in an individual region does not affect the trade-offs faced by any political decision maker, see below.
} 
We conjecture and later verify that policy choices are independent of the endogenous state variables, $\vec{s}_{t-1}$. Future policy choices therefore are unaffected by current policy choices.

Political decision makers at the regional and federal level perceive the economic environment differently. On the regional level they take policy choices by the federal government and in other regions, as well as factor prices and externalities, as given. On the federal level they take regional policy choices as given and account for the endogeneity of factor prices as well as externalities.

Formally, under the conjecture a regional decision maker in period $t$ takes $\left(w_{t}, w_{t+1}, R_{t}, R_{t+1}\right)$ as well as $s_{t-1}^{i j}$ and $\left(\vec{\tau}_{t}, \tau_{t}, x_{t}, \tau_{t+1}^{i j}, \vec{\tau}_{t+1}, \tau_{t+1}, x_{t+1}\right)$ as given and her objective is $\omega U_{t}^{i j, r} / \nu_{t}+$ $U_{t}^{i j, w}$. Effectively, she maximizes

$$
V_{t}^{i j} \equiv\left(\frac{\omega}{\nu_{t}}+1\right) \gamma_{t}^{j} \ln \left(a\left(e_{t}^{i j}, e_{t}\right)\right)+(1+\beta) \ln \left(\varphi_{t}^{i j}\right) \quad \text { s.t. } \quad(3)
$$

In contrast, the federal decision maker in period $t$ takes $\left(w_{t}, R_{t}\right)$ as well as $\vec{s}_{t-1}$ and $\left(\vec{\tau}_{t}, \vec{\tau}_{t+1}, \tau_{t+1}, x_{t+1}\right)$ as given and she is concerned with the average of $\omega U_{t}^{j, r} / \nu_{t}+U_{t}^{j, w}$ across the $J$ groups. Effectively, she maximizes

$$
\begin{aligned}
V_{t} \equiv & \sum_{j=1}^{J} \theta_{t}^{j}\left\{\left(\frac{\omega}{\nu_{t}}+1\right) \gamma_{t}^{j} \ln \left(g_{t}^{j}\right)+(1+\beta) \ln \left(\varphi_{t}^{j}\right)+\beta \ln \left(R_{t+1}\right)+\beta \mathbb{E}_{t}\left[\gamma_{t+1}^{j^{\prime}} \ln \left(g_{t+1}^{j^{\prime}}\right)\right]\right\}(8) \\
& \text { s.t. }(1),(2),(3),(4), k_{t+1}=s_{t} / \nu_{t+1} .
\end{aligned}
$$

We can now define politico-economic equilibrium (under the conjecture). ${ }^{21}$

Definition 2. A politico-economic equilibrium conditional on $z_{0}$ is given by a policy sequence $\left\{\vec{\tau}_{t}, \tau_{t}, x_{t}\right\}_{t \geq 0}$ and an allocation and price system such that

i. $\tau_{t}^{i j} \geq 0$ maximizes $V_{t}^{i j}$ and $\tau_{t}^{i j}=\tau_{t}^{j}$ for all $i, j, t$;

ii. $\left(\tau_{t}, x_{t}\right) \geq 0$ maximizes $V_{t}$ for all $t$; and

iii. the allocation and price system constitute a competitive equilibrium conditional on $z_{0}$ and $\left\{\vec{\tau}_{t}, \tau_{t}, x_{t}\right\}_{t \geq 0}$.

\section{Analysis}

\subsection{Substitutability, No Traditional Fiscal Federalism Motives}

To build intuition, we start with the case where spending by the federal and the regional governments are perfect substitutes, $a\left(e_{t}^{i j}, e_{t}\right)=e_{t}^{i j}+e_{t}$, and neither externalities nor heterogeneity are present, $\lambda=0$ and $\gamma_{t}^{j}=\gamma_{t} \forall j$. In this case, (2) and (3) imply

$$
g_{t}^{i j}=w_{t}\left(\tau_{t}^{i j}+\sigma x_{t}\right)+w_{t}\left(\tau_{t}-x_{t}\right)=w_{t}\left(\tau_{t}^{i j}+\tau_{t}+(\sigma-1) x_{t}\right) \forall i, j .
$$

\footnotetext{
${ }^{21}$ In general, politico-economic equilibrium requires that political decision makers anticipate future policy choices to be determined according to policy functions (mappings from the state into policy) and that optimal policy choices are consistent with policy functions evaluated at the state. Under the conjecture this consistency requirement is trivially satisfied.
} 
Absent heterogeneity in regional preferences and without externalities across regions, none of the traditional fiscal federalism motives for decentralization or centralization is present. Nevertheless, the equilibrium degree of centralization of tax collection generally is determinate. To see this, consider the derivative of the regional objective function $V_{t}^{i j}$ with respect to the regional tax rate, $\tau_{t}^{i j}$ (which equals $\tau_{t}^{j}$ in equilibrium), and the derivative of the federal objective function $V_{t}$ with respect to the federal tax rate, $\tau_{t}$. Since tax rates must be non-negative the derivative of $V_{t}^{i j}$ in (7) and of $V_{t}$ in (8) must be weakly negative in equilibrium,

$$
\begin{aligned}
& \left(\frac{\omega}{\nu_{t}}+1\right) \frac{\gamma_{t}}{\tau_{t}^{j}+\tau_{t}+(\sigma-1) x_{t}}-\frac{1+\beta}{\varphi_{t}^{j}} \leq 0 \quad \forall j \\
& \left(\frac{\omega}{\nu_{t}}+1\right) \frac{\gamma_{t}}{\tau_{t}^{j}+\tau_{t}+(\sigma-1) x_{t}}-\frac{1+\beta}{\varphi_{t}^{j}}+\mathcal{F}_{t} \leq 0,
\end{aligned}
$$

respectively, where $\mathcal{F}_{t} \equiv-\frac{\beta}{\varphi_{t}^{j}}\left(\epsilon_{R k}+\epsilon_{w k} \gamma_{t+1}\right)$ denotes the factor price effect that is internalized at the federal level. In addition, the corresponding complementary slackness conditions must be satisfied.

The terms in the first inequality represent the marginal benefit and cost, respectively, of a higher regional tax rate as perceived by voters at the regional level. The marginal benefit derives from higher public services which both old and young voters appreciate, and the marginal cost reflects reduced wealth and thus, consumption of workers.

In the second inequality, the first two terms represent the marginal benefit of higher public services and the direct marginal cost of lower consumption as perceived by voters in nationwide elections. The marginal benefit and the direct marginal cost are the same as those perceived on the regional level because of the uniformity of preferences and the absence of externalities.

The third term in the second inequality, $\mathcal{F}_{t}$, represents the indirect net benefit of higher taxes that young voters at nationwide elections internalize. This net benefit materializes in the subsequent period (thus the discounting) and works through the tax induced reduction in savings in all regions (note that $\mathrm{d} \ln \left(s_{t}^{j}\right) / \mathrm{d} \tau_{t}=-1 / \varphi_{t}^{j}$, see equation (4)). The benefit arises in the form of higher interest rates (reflected in $-\epsilon_{R k}$, which is positive), and the cost in the form of a lower tax base to fund public services in the future (reflected in $-\epsilon_{w k}$, which is negative) weighted by the preference for public services in the subsequent period, $\gamma_{t+1}$.

A comparison of the two inequalities implies that the equilibrium degree of centralization of tax collection, and the amount of taxes that are collected both are determinate unless $\mathcal{F}_{t}=0$. Since at least one of the tax rates $\tau_{t}^{j}$ and $\tau_{t}$ must be strictly positive in equilibrium (otherwise $g_{t}^{j}=0$ ), at least one of the two first-order conditions must hold with equality. But $\mathcal{F}_{t} \neq 0$ also implies that at most one first-order condition can hold with equality. It follows that either $\tau_{t}$ or $\tau_{t}^{j}$ equals zero. If $\mathcal{F}_{t}>0$ then the first-order condition with respect to $\tau_{t}$ holds with equality, that is $\tau_{t}$ is interior and $\tau_{t}^{j}=0$. If $\mathcal{F}_{t}<0$, in contrast, the first-order condition with respect to $\tau_{t}^{j}$ holds with equality, that is $\tau_{t}^{j}$ is interior $\forall j$ and $\tau_{t}=0$.

Importantly, this result holds although no traditional fiscal federalism motives are 
present. Determinacy results because voters at nationwide elections perceive different net benefits of taxation than voters in regional elections. For example, when lower savings drive up interest rates sufficiently strongly to render $\mathcal{F}_{t}>0$, then the federal government levies taxes because voters at nationwide elections internalize that taxation improves their inter temporal terms of trade. In contrast, when lower savings depress next period's wages sufficiently strongly and the preference for public services in the subsequent period is sufficiently high to render $\mathcal{F}_{t}<0$, then regional governments levy taxes because only voters at nationwide elections internalize the cost of taxation that results from lowering next period's tax base. ${ }^{22}$ A binding commitment for regions not to raise taxes would improve voters' welfare in that case.

Turning to grants, the derivative of $V_{t}$ in (8) with respect to $x_{t}$ must be non-negative as well,

$$
\left(\frac{\omega}{\nu_{t}}+1\right) \frac{\gamma_{t}(\sigma-1)}{\tau_{t}^{j}+\tau_{t}+(\sigma-1) x_{t}} \leq 0
$$

and the corresponding complementary slackness condition must be satisfied. This implies that $x_{t}=0$ when grants entail deadweight losses $(\sigma<1)$. If $\sigma=1$, in contrast, the equilibrium level of grants is indeterminate since perfect substitutability of spending across levels of government then implies that intergovernmental transfers do not affect the allocation.

We have characterized equilibrium policy. Note that we have verified our earlier conjecture that the policy functions are orthogonal to the endogenous state variables since the first-order (and complementary slackness) conditions do not involve the capital stock. We summarize these findings as our first main result:

Proposition 1. Consider the case with perfect substitutability and with no traditional fiscal federalism motives. Suppose that $\epsilon_{R k}+\epsilon_{w k} \gamma_{t+1} \neq 0$ such that $\mathcal{F}_{t} \neq 0$. Then, in equilibrium, only one level of government levies taxes. In particular, for $\epsilon_{R k}+\epsilon_{w k} \gamma_{t+1}<0$ (such that $\mathcal{F}_{t}>0$ ) only the federal government levies taxes and for $\epsilon_{R k}+\epsilon_{w k} \gamma_{t+1}>0$ (such that $\mathcal{F}_{t}<0$ ) only the regional governments levy taxes. Grants equal zero unless $\sigma=1$ in which case they are indeterminate.

Proposition 1 establishes that the equilibrium level of government that collects taxes in a federal state is determined even if none of the traditional fiscal federalism motives for decentralization or centralization of spending is present. We study next how this result is affected when we introduce the traditional fiscal federalism motives.

\subsection{Substitutability, Traditional Fiscal Federalism Motives}

Suppose next that regional preferences for public services are heterogeneous and government spending generates externalities across regions. We maintain the assumption of perfect substitutability, $a\left(e_{t}^{i j}, e_{t}\right)=e_{t}^{i j}+e_{t}$. The conforming cross-regional aggregator

\footnotetext{
${ }^{22}$ If labor were mobile, regional governments could perceive a marginal tax increase to reduce the tax base. Denoting by $\mathcal{X}_{t}$ this "tax competition" cost, our results would follow through, with taxation at the federal level an equilibrium outcome as long as $\mathcal{F}_{t}+\mathcal{X}_{t}>0$.
} 
$A\left(\vec{e}_{t}, e_{t}\right)$ is given by $A\left(\vec{e}_{t}, e_{t}\right)=\sum_{n} \theta_{t}^{n} e_{t}^{n}+e_{t}$ and as a consequence, public services in region $i$ in group $j$ equal $^{23}$

$$
g_{t}^{i j}=w_{t}^{1+\lambda}\left(\tau_{t}^{i j}+\tau_{t}+(\sigma-1) x_{t}\right)\left(\sum_{n=1}^{J} \theta_{t}^{n} \tau_{t}^{n}+\tau_{t}+(\sigma-1) x_{t}\right)^{\lambda} \forall i, j .
$$

Heterogeneity and the presence of externalities do not affect the first-order condition for regional policy makers (except that $\gamma_{t}$ is replaced by $\gamma_{t}^{j}$ ) because they take $A\left(\vec{e}_{t}, e_{t}\right)$ as given. However, these factors do change marginal costs and benefits as perceived by decision makers at the federal level. Heterogeneity implies that the derivative of $V_{t}$ in (8) is a non-trivial average of the policy consequences across regions: The marginal benefit of higher taxes varies by region, and due to regional variation of tax rates the effect of $\tau_{t}$ on capital accumulation works through region specific savings levels. The presence of externalities implies that the benefit of higher federal taxes that fund public services in a specific region also arise outside of this region.

Let $\bar{\gamma}_{t} \equiv \sum_{j} \theta_{t}^{j} \gamma_{t}^{t}$ denote the average preference for public services; $\bar{\tau}_{t} \equiv \sum_{j} \theta_{t}^{j} \tau_{t}^{j}$ the average regional tax rate; and $\bar{\varphi}_{t} \equiv \sum_{j} \theta_{t}^{j} \varphi_{t}^{j}$ the average tax wedge. The marginal benefit from higher federal taxes due to spending related externalities across regions can be expressed as $\mathcal{E}_{t} \equiv \lambda \bar{\gamma}_{t}\left(\omega / \nu_{t}+1\right) /\left(\bar{\tau}_{t}+\tau_{t}+(\sigma-1) x_{t}\right)$ and the marginal benefit due to general equilibrium effects now equals $\mathcal{F}_{t} \equiv-\beta / \bar{\varphi}_{t}\left(\epsilon_{R k}+\epsilon_{w k}(1+\lambda) \bar{\gamma}_{t+1}\right)$. Accordingly, the first-order conditions at the regional and federal level, respectively, now read

$$
\begin{gathered}
\left(\frac{\omega}{\nu_{t}}+1\right) \frac{\gamma_{t}^{j}}{\tau_{t}^{j}+\tau_{t}+(\sigma-1) x_{t}}-\frac{1+\beta}{\varphi_{t}^{j}} \leq 0 \quad \forall j, \\
\sum_{j=1}^{J} \theta_{t}^{j}\left\{\left(\frac{\omega}{\nu_{t}}+1\right) \frac{\gamma_{t}^{j}}{\tau_{t}^{j}+\tau_{t}+(\sigma-1) x_{t}}-\frac{1+\beta}{\varphi_{t}^{j}}\right\}+\mathcal{E}_{t}+\mathcal{F}_{t} \leq 0 .
\end{gathered}
$$

In addition, the complementary slackness conditions must be satisfied in equilibrium. Note that, under the assumption that policy functions are independent of $\vec{s}_{t-1}$, the fact that region $i$ of type $j$ in period $t$ might assume type $j^{\prime}$ in period $t+1$ does not affect decisions at the local level. For the federal government the types of individual regions are irrelevant; only regional averages enter its objective function and constraints.

The two inequalities imply that total tax collections and their composition across governments continue to be determinate in equilibrium. The first inequality implies that, if the regional tax rate in a region in group $j$ is strictly positive then the regional tax rate in all regions in groups with a stronger preference for public services must also be strictly positive (and higher). Since at least one of the tax rates $\tau_{t}^{j}$ and $\tau_{t}$ must be strictly positive in each typical region (otherwise $g_{t}^{j}=0$ ), and since it is generically not possible that all tax rates are strictly positive ${ }^{24}$, this leaves three possibilities: First, all regions impose strictly positive tax rates, $\tau_{t}^{j}>0 \forall j$, and $\tau_{t}=0$ and $\mathcal{E}_{t}+\mathcal{F}_{t}<0$. Second, all

\footnotetext{
${ }^{23}$ Our results are robust to specifying $A\left(\vec{e}_{t}, e_{t}\right)$ as a geometric rather than arithmetic average.

${ }^{24}$ Summing the first-order conditions for regional tax rates yields the sum in the first-order condition for the federal tax rate. Satisfying all first-order conditions with equality thus only is possible if $\mathcal{E}_{t}+\mathcal{F}_{t}=0$.
} 
regions impose zero regional tax rates, $\tau_{t}^{j}=0 \forall j$, and $\tau_{t}>0$ and $\mathcal{E}_{t}+\mathcal{F}_{t}>0$. And third, a strict subset of regions with the strongest preference for public services imposes strictly positive tax rates, $\tau_{t}^{j}>0$ for some but not all $j$, and $\tau_{t}>0$ and $\mathcal{E}_{t}+\mathcal{F}_{t}>0$.

The first-order condition for grants reads

$$
\left(\frac{\omega}{\nu_{t}}+1\right) \sum_{j=1}^{J} \theta_{t}^{j} \frac{\gamma_{t}^{j}(\sigma-1)}{\tau_{t}^{j}+\tau_{t}+(\sigma-1) x_{t}}+(\sigma-1) \mathcal{E}_{t} \leq 0
$$

which must hold in combination with the complementary slackness condition. Absent deadweight losses, grants therefore still are irrelevant. With deadweight losses, in contrast, the situation is more nuanced. If $\sigma<1$ and the effects due to externalities, $\mathcal{E}_{t}$, are not too negative then $x_{t}=0$ as before. But if $\sigma<1$ and the effects due to externalities are very negative then the federal government might want to employ grants, $x_{t}>0$, as an instrument to discourage regional government spending. Since federal grants require federal taxes, this outcome also requires $\mathcal{E}_{t}+\mathcal{F}_{t}>0 .^{25}$

Note that again, the conjecture that policy functions are orthogonal to the endogenous state is verified. We may therefore summarize the results as follows:

Proposition 2. Consider the case with perfect substitutability and with traditional fiscal federalism motives. For $\mathcal{E}_{t}+\mathcal{F}_{t}>0$ the federal government levies taxes and potentially, a strict subset of regions (those groups with the highest preference for public services) levies differentiated taxes as well; grants are only used in the presence of strong negative externalities, unless they entail no deadweight losses. For $\mathcal{E}_{t}+\mathcal{F}_{t}<0$ all regional governments levy differentiated taxes but the federal government does not; accordingly, grants equal zero. Parametric conditions determine which case occurs. Conditional on $x_{t}$, all tax rates are uniquely determined.

Proof. See appendix B for the parameter conditions under which the cases $\mathcal{E}_{t}+\mathcal{F}_{t}>0$ or $\mathcal{E}_{t}+\mathcal{F}_{t}<0$ occur, as well as the parameter condition for all regional tax rates to equal zero.

\subsection{Limited Substitutability}

Propositions 1 and 2 establish unique equilibrium tax rates for all governments, $\left(\vec{\tau}_{t}, \tau_{t}\right)$, as long as $\mathcal{F}_{t} \neq 0$ or $\mathcal{E}_{t}+\mathcal{F}_{t} \neq 0$, respectively. If grants are restricted to equal zero, $x_{t}=0$, as is the case in the traditional fiscal federalism literature, or when grants entail deadweight losses, then the propositions also imply unique equilibrium spending levels for each level of government. Absent this restriction, however, and if grants do not entail deadweight losses the composition of spending by level of government is indeterminate.

As is clear from the discussions leading to propositions 1 and 2 the source of the irrelevance of grants (except for the odd case with strong negative externalities in proposition 2) is the assumption of perfect substitutability. We now relax this assumption and

\footnotetext{
${ }^{25}$ Of course, in a richer model the federal government would prefer to spend resources on other public services that do not generate negative externalities rather than "burning money" by means of grants.
} 
introduce strict concavity in the aggregator function $a(\cdot)$, reflecting complementarities in government spending or in the preferences for public services, or constitutional restrictions. ${ }^{26}$ This gives a natural role to grants: When the federal government perceives a more favorable trade-off between taxation and spending than regional governments then it transfers resources to the latter, such that regional spending increases hand in hand with federal spending.

For tractability, we assume that the aggregator function $a(\cdot)$ is of the Cobb-Douglas form with exponent $\delta$ on regional spending, $a\left(e_{t}^{i j}, e_{t}\right)=\left(e_{t}^{i j}\right)^{\delta}\left(e_{t}\right)^{1-\delta}$. The conforming cross-regional aggregator $A\left(\vec{e}_{t}, e_{t}\right)$ is given by $A\left(\vec{e}_{t}, e_{t}\right)=\prod_{n=1}^{J}\left(\left(e_{t}^{n}\right)^{\delta}\left(e_{t}\right)^{1-\delta}\right)^{\lambda \theta_{t}^{n}}$ and public services therefore equal

$$
g_{t}^{i j}=w_{t}^{1+\lambda}\left(\tau_{t}^{i j}+\sigma x_{t}\right)^{\delta}\left(\tau_{t}-x_{t}\right)^{(1-\delta)(1+\lambda)} \prod_{n=1}^{J}\left(\tau_{t}^{n}+\sigma x_{t}\right)^{\delta \lambda \theta_{t}^{n}} \forall i, j .
$$

The first-order conditions with respect to a regional tax rate and the federal tax rate, respectively, now read

$$
\begin{gathered}
\left(\frac{\omega}{\nu_{t}}+1\right) \frac{\gamma_{t}^{j} \delta}{\tau_{t}^{j}+\sigma x_{t}}-\frac{1+\beta}{\varphi_{t}^{j}} \leq 0 \forall j \\
\sum_{j=1}^{J} \theta_{t}^{j}\left\{\left(\frac{\omega}{\nu_{t}}+1\right) \frac{\gamma_{t}^{j}(1-\delta)}{\tau_{t}-x_{t}}-\frac{1+\beta}{\varphi_{t}^{j}}\right\}+\mathcal{E}_{t}+\mathcal{F}_{t} \leq 0,
\end{gathered}
$$

where the marginal benefit from higher federal taxes due to externalities now is given by $\mathcal{E}_{t} \equiv \lambda \bar{\gamma}_{t}\left(\omega / \nu_{t}+1\right)(1-\delta) /\left(\tau_{t}-x_{t}\right)$. The equilibrium factor price effects $\mathcal{F}_{t}$ are unchanged from before. In addition to these first-order conditions and the complementary slackness conditions the following first-order condition for grants must be satisfied in equilibrium:

$$
\sigma \delta \sum_{j=1}^{J} \frac{\theta_{t}^{j}\left(\gamma_{t}^{j}+\lambda \bar{\gamma}_{t}\right)}{\tau_{t}^{j}+\sigma x_{t}}-\frac{(1-\delta)(1+\lambda) \bar{\gamma}_{t}}{\tau_{t}-x_{t}} \leq 0
$$

Due to the complementarities (and the restriction that $x_{t}$ is non-negative) the federal tax rate must be positive in equilibrium. In contrast, the regional tax rates need not be positive unless grants equal zero.

Consider the case where all tax rates are interior, $\tau_{t}, \tau_{t}^{j}>0 \forall j$, such that all first-order conditions for taxes hold with equality. To constitute an equilibrium these interior tax rates have to be consistent with the remaining equilibrium condition that the marginal benefit of grants is weakly negative. In appendix C, we derive the parametric condition that must be satisfied for this to be the case. For homogeneous preferences, this condition,

\footnotetext{
${ }^{26}$ Spending complementarities could reflect informational frictions. If some governments can better provide certain public services than others then allocating the responsibility for spending to specific levels of government affects the total provision. For a critique of the notion of insurmountable information frictions across levels of government, see Treisman (2007). In appendix A, we provide micro foundations for complementarities that derive from constitutional restrictions.
} 
which trades-off static and dynamic externalities against deadweight losses, reduces to

$$
\frac{\beta}{1+\beta}\left(\epsilon_{R k}+\epsilon_{w k}(1+\lambda) \bar{\gamma}_{t+1}\right) \geq \sigma(1+\lambda)-1
$$

If the condition is met (which is guaranteed, for example, if $\sigma$ is sufficiently small) then the equilibrium indeed features positive tax rates at the federal level and in all regions while grants are absent. ${ }^{27}$ If the condition is violated, in contrast, (which is more likely, for example, if $\mathcal{F}_{t}$ or $\lambda$ are sufficiently large), then tax rates cannot be strictly positive in all regions. Regions with a low valuation of public services do not levy taxes in this case, and grants are strictly positive.

Again, the conjecture that policy functions are orthogonal to the endogenous state is verified. We summarize the results as follows:

Proposition 3. Consider the case with limited substitutability and with traditional fiscal federalism motives. The federal government always levies taxes. When the parametric condition in appendix $\mathrm{C}$ is satisfied then all regions levy taxes as well, and grants generically equal zero. When the opposite condition holds, then grants are strictly positive and they fully crowd out taxes in regions with a low valuation of public services. Grants are more likely to be used the larger general equilibrium price effects, the lower dead-weight losses, the higher static externalities, and the larger the dispersion of preferences across regions.

Proof. See appendix C.

\section{Extensions}

\subsection{Capital Income Taxes}

It is instructive to compare the implications of the model under the alternative assumption that governments resort to capital rather than labor income taxes. At the time when capital income taxes are decided upon and implemented, they only affect consumption of the old, but not savings of the young (anticipated capital taxes might affect savings but when households take savings decisions the relevant tax rates are beyond the control of political decision makers). As a consequence, with capital income taxation the federal government perceives no equilibrium factor price effects, $\mathcal{F}_{t}=0$.

Maintaining the notation $\varphi_{t}^{j}$ for the tax wedge in a typical region of type $j$, the only other change (beyond $\mathcal{F}_{t}=0$ ) in the first order conditions for taxes concerns the weight that governments place on the cost of taxation: $(1+\beta)$ is replaced by $\frac{\omega}{\nu_{t}} \cdot{ }^{28}$ The first-order condition for grants is unaffected since it is independent of general equilibrium effects.

\footnotetext{
${ }^{27}$ In the non-generic case where the parametric condition is satisfied with equality, grants are indeterminate.

${ }^{28}$ Although tax bases of labor and capital income taxes are different, implying different levels of spending for a given tax rate, voters face a similar trade-off between the marginal costs and benefits of taxation since preferences are logarithmic.
} 
When public spending is perfectly substitutable across levels of government, externalities are absent, $\mathcal{E}_{t}=0$, and preferences for public services are homogenous across regions, then total taxes are determinate in equilibrium but the degree of centralization is not. As before, grants are indeterminate unless they are wasteful, in which case $x_{t}=0$. If there are externalities and preferences are heterogeneous, then externalities must be positive, $\mathcal{E}_{t}>0$, for the federal government to levy taxes. Again, only a strict subset of regions levies differentiated taxes in this case. If grants entail deadweight losses they are not used, otherwise their equilibrium size is indeterminate. ${ }^{29}$

When there are complementarities in government spending, we find again that the federal government always levies taxes as do a subset of regional governments. As before, there is a parametric conditions for grants not to be used. Intuition can be gained by considering the special case of homogenous preferences. Grants are not used in this case if

$$
\sigma(1+\lambda)-1<0
$$

that is if deadweight losses associated with transferring resources to local governments outweigh positive externalities.

\subsection{Matching Grants}

In contrast to uniform, or block, grants, federal governments sometimes use matching grants that provide local governments with resources in proportion to what they themselves spend on a particular outlay. We consider the case in which matching grants are provided at the same rate on all possible expenditures, such that if local government $i$ in a region of type $j$ spends $w_{t} \tau_{t}^{i j}$, the federal government transfers $x_{t} w_{t} \tau_{t}^{i j}$ and spending is given by

$$
e_{t}=w_{t}\left(\tau_{t}-x_{t} \bar{\tau}_{t}\right), \quad e_{t}^{i j}=w_{t} \tau_{t}^{i j}\left(1+\sigma x_{t}\right), \quad e_{t}^{j}=w_{t} \tau_{t}^{j}\left(1+\sigma x_{t}\right) \quad \forall i, j .
$$

In appendix D we analyze the model with matching grants. The following proposition summarizes the findings:

Proposition 4. With matching grants, perfect substitutability and no traditional fiscal federalism motives the results of proposition 1 apply. With perfect substitutability and with traditional fiscal federalism motives, there are no federal taxes, and thus no grants if $\mathcal{E}_{t}+\mathcal{F}_{t}<0$. The parameter restriction for this case is the same that was found in appendix B for proposition 2. Grants are used when they entail low deadweight losses. In this case, they fully crowd out local taxes in at least one type of region. Grants are also used in the presence of strong negative externalities. With limited substitutability, all tax rates are positive. When a parameter condition specified in appendix D is satisfied, grants are not used.

\footnotetext{
${ }^{29}$ The result found earlier that grants could be used to "waste" resources requires both a desire to reduce provision (due to negative externalities) and an incentive to tax at the central level, the combination of which is impossible when $\mathcal{F}_{t}=0$.
} 
We conclude that the predictions of the model with uniform grants and with matching grants qualitatively are largely identical. The main difference to the model with uniform grants is that with perfect substitutability and with traditional fiscal federalism motives, grants are more likely to be used when $\mathcal{E}_{t}+\mathcal{F}_{t}>0$. With limited substitutability and homogeneous preferences, the condition for the absence of grants is given by the same condition as in the case with uniform grants.

\section{Quantitative Implications and Empirical Evidence}

Wallis (2000) documents that the United States passed through three different eras of government finance. From 1790 until about 1842 state governments were the most active and financed themselves through asset income, primarily from tolls on canals, dividends from bank stock, and revenue from land sales. By 1842 several states were in default on their debts.

To meet this crisis, state governments resorted to property taxes and retreated from infrastructure investments. This was met with an increase in importance of local governments that also mainly resorted to property taxes for their funding. By the eve of the Great Depression, local governments collected over half of the tax revenues raised by all levels of government and property taxes accounted for $42 \%$ of revenues at all levels of government. During these first two eras, the federal government's main source of revenue were tariffs, and on a smaller scale, property taxes.

The Great Depression and the New Deal marked the birth of the current fiscal system. On the revenue side this system is characterized by the reliance on income and sales taxes at the federal and state levels. ${ }^{30}$ While income taxes only became feasible after the ratification of the Sixteenth Amendment in $1913,{ }^{31}$ and accounted for less than $10 \%$ of all government revenues in 1933, this share rose to more than $50 \%$ by the early 1940 s. In parallel, grants grew from negligible levels before 1933 to $9.4 \%$ of federal expenditures in 1940.

Summarizing this evidence from the middle of the nineteenth century onwards, we see a transition around the time of the Great Depression from tariffs and property taxes to income taxation, alongside an increase in taxation by the federal government and the introduction of federal grants. Wallis (2000) argues that this transition might reflect the fact that federal, state, and local governments face differential costs to raise revenues from different sources.

The model offers a potential explanation for the emergence of grants in parallel to the shift from property to income taxation. This explanation emphasizes that the ratification of the Sixteenth Amendment in 1913 opened the way for a form of taxation-labor income taxation - that generates general equilibrium effects and as a consequence, renders federal taxation and grants politically more attractive.

\footnotetext{
${ }^{30}$ Income taxes include individual, corporate, and payroll taxes.

${ }^{31}$ The Sixteenth Amendment states: "The Congress shall have power to lay and collect taxes on incomes, from whatever source derived, without apportionment among the several States, and without regard to any census or enumeration." In 1916 the U.S. Supreme Court upheld the constitutionality of tax legislation enacted based on this amendment.
} 


\begin{tabular}{lcccccccc}
\hline \hline & & 1985 & & 1990 & & 1996 & & 2006 \\
& Obs. & \% in favor & Obs. & \% in favor & Obs. & in favor & Obs. & \% in favor \\
\hline Total & 666 & 0.820 & 1182 & 0.782 & 1293 & 0.834 & 1483 & 0.633 \\
Urban & 540 & 0.807 & 1014 & 0.775 & 1163 & 0.831 & 1293 & 0.627 \\
Rural & 126 & 0.873 & 168 & 0.821 & 130 & 0.861 & 190 & 0.674 \\
\hline \hline
\end{tabular}

Table 1: Attitudes towards government spending cuts.

To check the quantitative merits of this explanation we calibrate the model with spending complementarities and simulate it. We assume that one period in the model corresponds to 30 years in the data, posit a Cobb-Douglas production function for the final good, and use the following parameter values: Based on findings in Piketty and Saez (2003) we let the capital share in the production function be 0.2815 . We set $\nu_{t}$ to the 30-year gross U.S. population growth rate and use Census Bureau data. From GonzalezEiras and Niepelt (2008) we take $\omega=0.9176$. In the benchmark calibration we assume $\lambda=0$.

We calibrate the remaining parameters based on moment predictions of the model. We assume that there are two types of regions, "urban" and "rural," and we proxy the share of urban regions, $\theta_{t}^{1}$, with the average urbanization rate as reported by the Census Bureau. The motivation to distinguish regions by urban vs. rural character is twofold. On the one hand, the distinction seems relevant for observed patterns of political support. For example, Frank (2004) argues that low-income Americans living in rural areas vote strongly Republican even though the Republican party's economic platform cuts against their economic interests. We interpret this behavior as reflecting a lower preference for government spending in rural areas. ${ }^{32}$ On the other hand, the distinction also seems to be borne out by survey evidence. Data on attitudes towards public spending collected by The General Social Survey in the years 1985, 1990, 1996, and 2006 indicates that respondents in rural areas supported government spending to a lesser extent than respondents in rural areas, see Table $1 .{ }^{33}$

The urban-vs.-rural distinction also is consistent with indirect evidence that blends data on state level spending and an implication of the model. Recall that the model with uniform grants predicts regions with lower valuations for public services to have a higher ratio of grants relative to regional tax revenues. If urbanization is positively correlated with the valuation of public services, then it should go hand in hand with a decrease of

\footnotetext{
${ }^{32}$ Other observers have argued that voters care more about moral than economic issues. See Ansolabehere, Rodden and Snyder Jr. (2006) for a critical discussion of the "culture war" interpretation of these voting patterns.

${ }^{33}$ The survey is conducted yearly by The National Data Program for the Social Sciences. Respondents were asked if they favored or not cuts in government spending. We take the fraction of those answering "strongly in favor of" and "in favor of" as a measure of the intensity of preferences for lower spending.
} 


\begin{tabular}{lcc}
\hline \hline & Grants to local revenue & Grants per capita \\
\hline \multirow{2}{*}{ Urbanization } & $-0.309^{*}$ & $-2.66^{* * *}$ \\
& $(0.182)$ & $(0.981)$ \\
Income per capita & 0.295 & 2.44 \\
& $(0.246)$ & $(0.700)$ \\
State FE & YES & YES \\
Time FE & YES & YES \\
$\mathrm{R}^{2}$ & 0.075 & 0.554 \\
Observations & 98 & 98 \\
\hline \hline
\end{tabular}

Table 2: Panel regressions (robust standard errors in parenthesis, ${ }^{*}$ and $* * *$ indicate significance at the 0.1 and 0.01 levels respectively). Urbanization is associated with a lower importance of grants.

that ratio. We test this prediction using U.S. state level data for 1969 and 2008 in a panel regression of the ratio of federal grants to direct general revenue in state and local governments on urbanization (controlling for state income per capita), see Table 2. As expected, we find that an increase in urbanization is associated with a decrease in the ratio of grants to state and local revenues. ${ }^{34}$

To calibrate the preference for public services as well as $\beta, \delta$ and $\sigma$, we use the firstorder conditions for $\tau_{t}^{1}$ and $x_{t}$ in 1940 and $\tau_{t}, \tau_{t}^{1}$ and $x_{t}$ in 2000 to match the GDP-share of grants, the GDP-share of total (state and regional) spending, and the ratio of federal to regional spending in the year 2000, as well as the ratios of regional spending and grants to GDP in the year $1940 .{ }^{35}$ We assume that grants are used in 1940 and 2000 such that in those two periods regions with low valuation-rural regions - do not tax. We allow preferences for public services to change over time at a constant rate. In addition, we use a moment condition for the Euler equation in steady state (see Gonzalez-Eiras and Niepelt, 2008). ${ }^{36}$

\footnotetext{
${ }^{34}$ We use the following data sources: The ratio of federal grants to state and local direct general revenue, as well as grants per capita for 1969 are taken from Dales (1970); grants for 2008 from the Census Bureau's Consolidated Federal Funds Report for Fiscal Year 2008, Table 4 (www.census.gov/prod/2009pubs/cffr-08.pdf); and state and local government finances for 2008 from the Census Bureau (www.census.gov/govs/local/historical_data_2008.html). State income per capita relative to national is taken from the Bureau of Economic Analysis (www.bea.gov/itable). Population and urbanization data comes from the Census Bureau (www.census.gov). We use 2008 data to avoid problems with the Great Recession, and we use data for the year 1969 rather than 1970 since the table in Dales (1971) appears to contain a typo in the entry for Colorado. We exclude the District of Columbia as its urbanization is $100 \%$ in both periods.

${ }^{35}$ Data comes from BEA.

${ }^{36}$ We impose the 30-year gross interest rate $R=2.443$. See Gonzalez-Eiras and Niepelt (2008) for
} 


\begin{tabular}{cccccc}
\hline \hline$\beta$ & $\delta$ & $\gamma_{2000}^{1}$ & $\gamma_{2000}^{2}$ & $\gamma_{t+1}^{j} / \gamma_{t}^{j}$ & $\sigma$ \\
\hline 0.5882 & 0.4915 & 0.7434 & 0.0176 & 1.2225 & 0.9365 \\
\hline \hline
\end{tabular}

Table 3: Calibration.

Table 3 lists the calibrated parameters. The $\beta$ value corresponds to an annual discount factor of approximately 0.982 . Deadweight losses are estimated to equal around $6.4 \%$. The calibration for $\delta$ suggests an almost equal role for federal and regional spending in the provision of public services. To meet the requirement that rural areas do not levy taxes they must have a low preference for the public service, of approximately $2.4 \%$ of the corresponding parameter for urban areas. ${ }^{37}$

To replicate the secular increase in government spending between 1940 and 2000, the model requires the preference for public services to grow at about $0.67 \%$ per year. This is qualitatively consistent with Wagner's law and with the evolution over time of attitudes towards spending cuts, as reported in Table 1 . If we impose $\theta_{t}^{1}=\theta_{t}^{2}$ (implying no trend in the cross-regional distribution of preferences, as proxied by the trend in urbanization) the calibration implies a significantly higher rate of growth for the preference parameters $\gamma_{t}^{j}$, of about $1.36 \%$ per year. This shows clearly that increased urbanization helps to explain the data because it implies that the average valuation of public services increases. In contrast, imposing a constant population growth rate has a negligible effect on the calibrated $\gamma_{t}^{j}$ s. Intuitively, in the model both workers and retirees benefit from public services. Ageing therefore has second order effects on the trade-off between the benefit from spending and the cost of taxation.

Figures 1, 2, and 3 illustrate the model predictions and make clear that the model is able to replicate the long-term trend and co-movement of the fiscal variables. In particular the model predicts that grants would continue to increase up to approximately $5.5 \%$ of GDP by 2060. These predictions are robust to changes in all parameters except $\lambda$ and $\sigma$. When externalities are assumed to be negative, say $-2 \%$, then grants are predicted to increase to $7.3 \%$ of GDP in 2060 with regional revenue stabilized at current levels. If externalities are assumed to be positive, in contrast, say $3 \%$, then the model predicts grants to level off at around 4\% of GDP in 2050 and regional revenue to continue increasing almost at its current rate.

When we exogenously impose a higher value for $\sigma$ (and eliminate a moment condition in the calibration) predicted regional taxes after the year 2010 fall and predicted federal taxes and grants strongly increase towards the end of the forecast horizon. Imposing a lower value for $\sigma$ generates a time series for grants that levels off and eventually reverts

\footnotetext{
details.

${ }^{37}$ This feature is robust to assuming matching grants. A calibration under that assumption also requires a large disparity in preferences across types of regions.
} 


\section{Total spending, share of GDP}

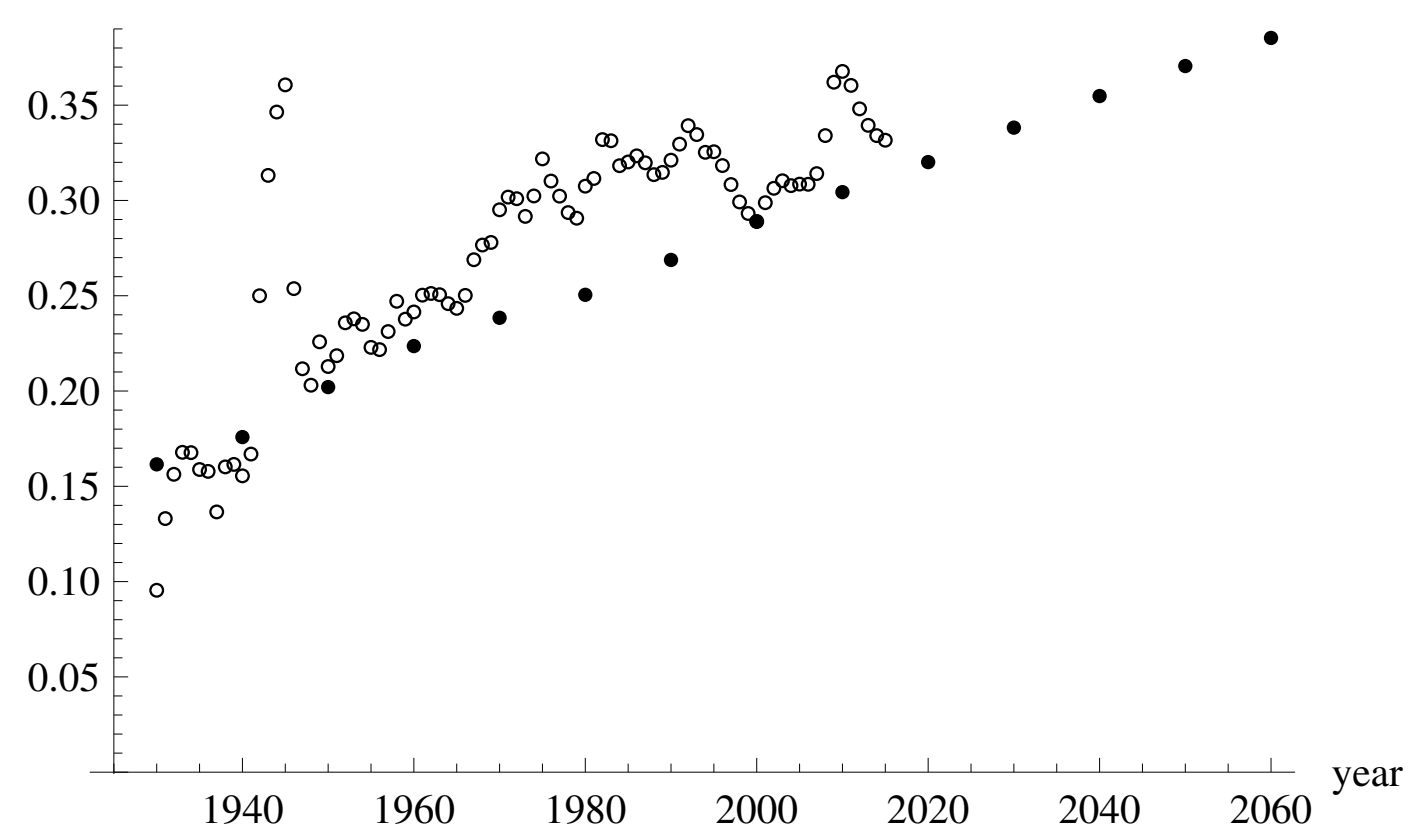

Figure 1: Total spending: Data (circles) and model predictions (dots).

\section{Average regional revenues, share of GDP}

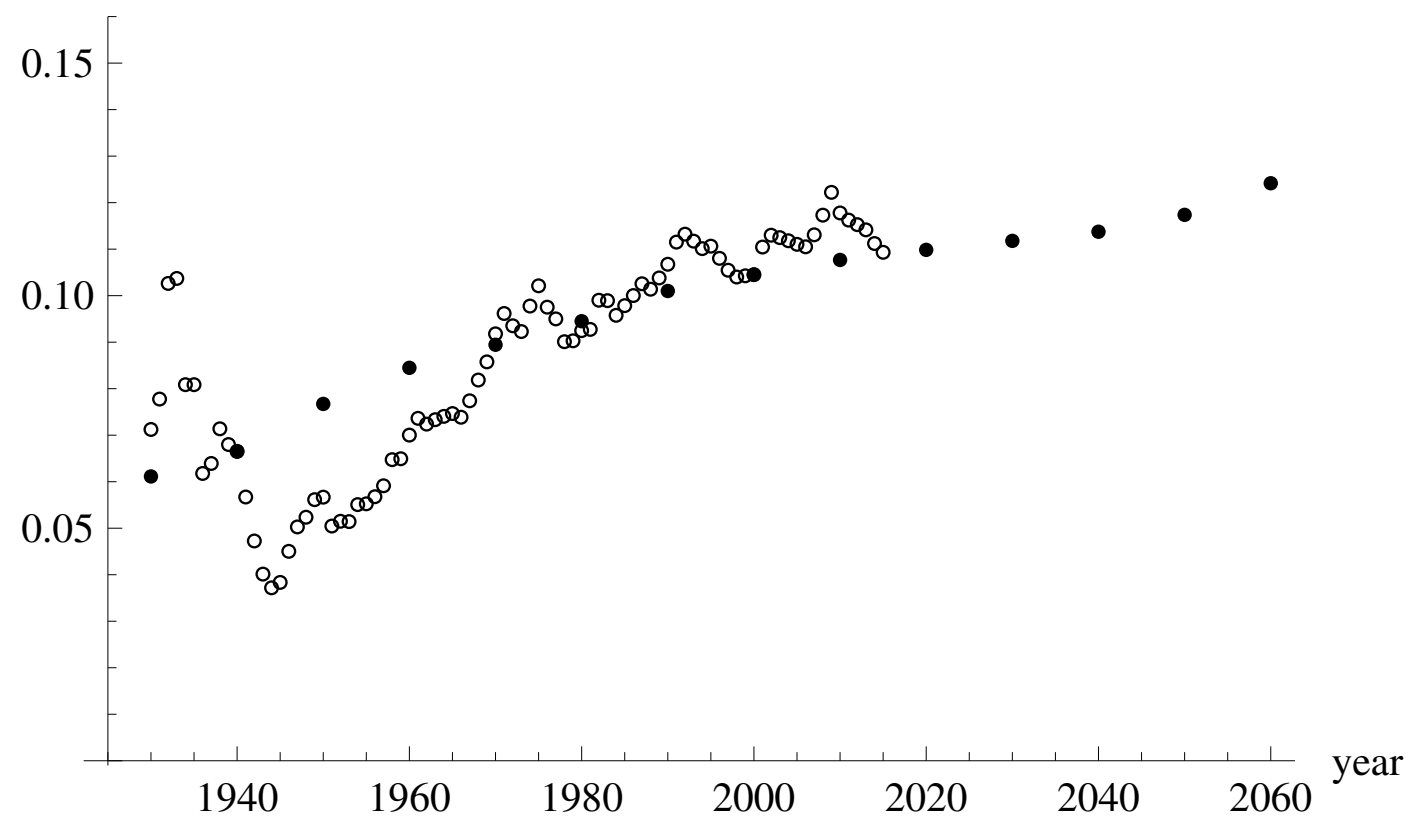

Figure 2: Regional revenues: Data (circles) and model predictions (dots). 


\section{Federal grants, share of GDP}

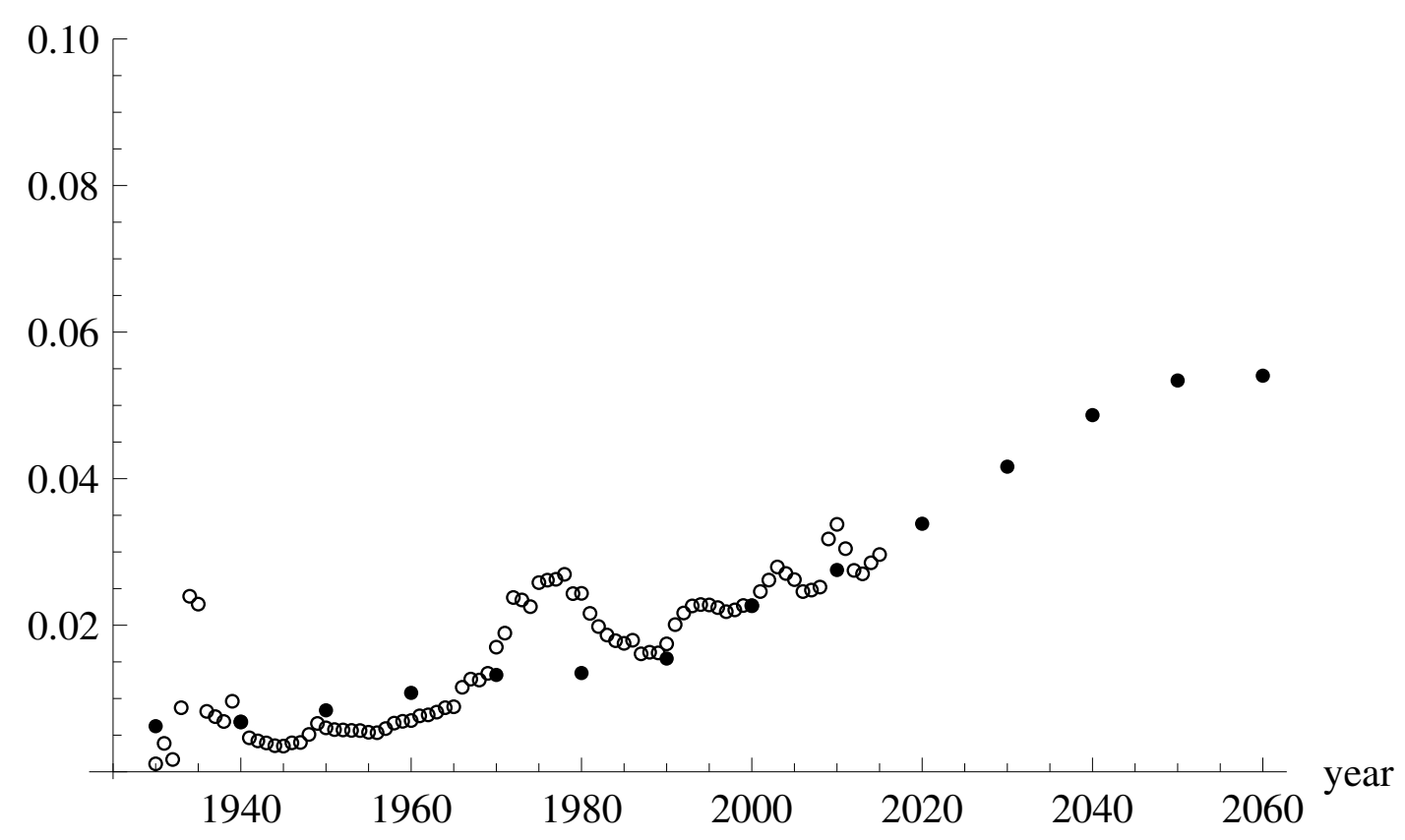

Figure 3: Federal Grants: Data (circles) and model predictions (dots).

back to lower values. This is driven by the fact that with lower deadweight losses, the federal government has a stronger incentive to provide grants, and these crowd out local spending.

Based on the calibration reported in table 3, we also compute a backward out-of-sample forecast and conduct a counterfactual analysis. First, we establish that according to the model, grants would not have been employed in the year 1910 given that mostly property taxes were in place and thus, general equilibrium price effects were minor. Specifically, we solve for politico-economic equilibrium in an economy with capital income taxes and show that in this economy, in the year 1910, grants would have been absent, in line with the data.

Second, we compute the choice of fiscal instruments in the year 2000 under the assumption that political decision makers at the federal level did not perceive the general equilibrium effects of labor income taxation. We find that in this case, the federal government does not make use of grants and federal taxes are about 6 percentage points lower, partially compensated by regional taxes that are about 4 percentage points higher. We summarize these latter findings in table 4.

\section{Concluding Remarks}

What determines the degree of centralization of tax collections in a federal state? We have argued that differences in the perceived cost of taxation across levels of government 


\begin{tabular}{lccc}
\hline \hline & $\tau_{2000}$ & $x_{2000}$ & $\bar{\tau}_{2000}$ \\
\hline Baseline & 0.2587 & 0.0333 & 0.1045 \\
Counterfactual & 0.1858 & 0.0000 & 0.1454 \\
\hline \hline
\end{tabular}

Table 4: Implications of general equilibrium effects for policy outcomes.

constitute a possible candidate. While such differences may arise from various sources we have emphasized one that is inherently dynamic, relating to the fact that tax policy at the national level induces general equilibrium effects on interest rates and wages. We have also argued that in combination with traditional motives for the centralization or not of government spending, cost differences of taxation provide a natural motive for inter governmental grants.

Our simple framework abstracts from cross-regional insurance, redistribution, and many other features that are present in federalist states. Given this simplicity, the predictive power of the model when calibrated to match U.S. data is reassuring. Trends in demographics and urbanization can account for the increase of the GDP-shares of total government spending, average regional revenues, and federal grants since the early 20th century. The projected paths for the exogenous variables implies that grants as a share of GDP will continue to increase to approximately $5.5 \%$ by 2016 . A counter factual analysis highlights the quantitative importance of general equilibrium effects. It predicts that grants would not be used and tax rates would differ by almost $30 \%$ if the federal government did not internalize these effects.

Two extensions of the model presented in this paper appear to be of particular interest. First, the setup could be enriched to admit productivity differences across regions, generating a role for cross-regional insurance and redistribution. Such an extension could be useful to study the determinants of redistributive federal grants and the consequences of cross-regional inequality, for example in the context of German unification or European integration.

Second, the option to issue government debt for tax smoothing or tax burden shifting purposes could be introduced both at the federal and the regional level. Governments would hold conflicting views about the relative cost and benefit of public debt since regional policymakers do not internalize the general equilibrium effects of deficits on factor prices. As a consequence, the federal government might employ grants (and deficits) to influence both regional taxes and deficits. We leave these extension for future work. 


\section{A Derivation of Aggregator Functions}

The functional form assumptions we adopt are special cases of the specification

$$
g_{t}^{i j}=\left(\int_{0}^{\delta}\left(\frac{e_{t}^{i j}(l)}{\delta}\right)^{\kappa} \mathrm{d} l+\int_{\delta}^{1}\left(\frac{e_{t}(l)}{1-\delta}\right)^{\kappa} \mathrm{d} l\right)^{\frac{1}{\kappa}} \times\left(\sum_{n=1}^{J} \theta_{t}^{n}\left(\int_{0}^{\delta}\left(\frac{e_{t}^{n}(l)}{\delta}\right)^{\kappa} \mathrm{d} l+\int_{\delta}^{1}\left(\frac{e_{t}(l)}{1-\delta}\right)^{\kappa} \mathrm{d} l\right)\right)^{\frac{\lambda}{\kappa}}
$$

where $\kappa \equiv(\eta-1) / \eta$ and $\eta \geq 0$. The interpretation is as follows: The public service is an aggregate that reflects spendings at the federal and the regional level on a continuum of goods indexed by $l \in[0,1]$. We assume a constant elasticity of substitution, $\eta \geq 0$, between types of goods (reflecting voters' preferences or technology in the production of the public service). The constitution prescribes that goods with index $l \in[0, \delta]$ must be provided (but not necessarily financed) by the regional government while goods with index $l \in(\delta, 1]$ must be provided by the federal government where $0<\delta<1$. $^{38}$

Efficiency requires that every government provides the same amount of each good under its control, $e_{t}^{i j}(l) \perp l$ for all $l \in[0, \delta]$ and $e_{t}(l) \perp l$ for all $l \in(\delta, 1]$ implying

$$
g_{t}^{i j}=\left(\delta\left(\frac{e_{t}^{i j}}{\delta}\right)^{\kappa}+(1-\delta)\left(\frac{e_{t}}{1-\delta}\right)^{\kappa}\right)^{\frac{1}{\kappa}} \times\left(\sum_{n=1}^{J} \theta_{t}^{n}\left(\delta\left(\frac{e_{t}^{n}}{\delta}\right)^{\kappa}+(1-\delta)\left(\frac{e_{t}}{1-\delta}\right)^{\kappa}\right)\right)^{\frac{\lambda}{\kappa}}
$$

The first term on the right-hand side of the preceding equation is defined as $a\left(e_{t}^{i j}, e_{t}\right)$ and the second term as $A\left(\vec{e}_{t}, e_{t}\right)^{\lambda}$.

For $\eta \rightarrow \infty(\kappa \rightarrow 1)$ the case of perfect substitutes follows,

$$
g_{t}^{i j}=\left(e_{t}^{i j}+e_{t}\right) \times\left(\sum_{n=1}^{J} \theta_{t}^{n} e_{t}^{n}+e_{t}\right)^{\lambda}
$$

The constitutional restriction (encapsulated in the parameter $\delta$ ) is irrelevant in this case. For $\eta \rightarrow 0$, the Leontieff case results. ${ }^{39}$ For $\eta=1$, the Cobb-Douglas specification follows,

$$
g_{t}^{i j}=\left(e_{t}^{i j}\right)^{\delta}\left(e_{t}\right)^{(1-\delta)(1+\lambda)} \prod_{n=1}^{J}\left(e_{t}^{n}\right)^{\delta \lambda \theta_{t}^{n}} \times \frac{1}{\Psi} .
$$

In the main text we drop the constant term $\Psi \equiv \delta^{\delta(1+\lambda)}(1-\delta)^{(1-\delta)(1+\lambda)}$ as it is irrelevant, due to the logarithmic utility assumption.

\section{B Proof of Proposition 2}

Consider the case where all regions levy positive taxes $\left(\tau_{t}^{j}>0 \forall j\right.$, first-order conditions with respect to $\tau_{t}^{j}$ hold with equality), the federal government does not collect taxes

\footnotetext{
${ }^{38}$ If there were a third category of goods to which both governments could simultaneously contribute then only the government for which benefits outweigh the costs the most would contribute, due to perfect substitutability. As a consequence, the formulation in the text applies.

${ }^{39}$ In this case we find $g_{t}^{i j}=w_{t}^{1+\lambda} \min \left[\frac{\tau_{t}-x_{t}}{1-\delta}, \frac{\tau_{t}^{i j}+\sigma x_{t}}{\delta}\right] \times \min \left[\frac{\tau_{t}-x_{t}}{1-\delta}, \frac{\min _{n} \tau_{t}^{n}+\sigma x_{t}}{\delta}\right]^{\lambda}$.
} 
$\left(\tau_{t}=0, \mathcal{E}_{t}+\mathcal{F}_{t}<0\right)$, and as a consequence grants equal zero $\left(x_{t}=0\right)$. Interior regional tax rates imply

$$
\tau_{t}^{j}=\frac{\left(\frac{\omega}{\nu_{t}}+1\right) \gamma_{t}^{j}}{\left(\frac{\omega}{\nu_{t}}+1\right) \gamma_{t}^{j}+1+\beta} \forall j, \quad \bar{\tau}_{t}=\sum_{j=1}^{J} \theta_{t}^{j} \frac{\left(\frac{\omega}{\nu_{t}}+1\right) \gamma_{t}^{j}}{\left(\frac{\omega}{\nu_{t}}+1\right) \gamma_{t}^{j}+1+\beta} .
$$

Letting $\Lambda_{t+1} \equiv\left(\epsilon_{R k}+\epsilon_{w k}(1+\lambda) \bar{\gamma}_{t+1}\right)$ and $\Omega_{t} \equiv\left(\omega / \nu_{t}+1\right)$, the restriction $\mathcal{E}_{t}+\mathcal{F}_{t}<0$ implies $\frac{\lambda \bar{\gamma}_{t} \Omega_{t}}{\bar{\tau}_{t}}-\frac{\beta}{1-\bar{\tau}_{t}} \Lambda_{t+1}<0$, and thus the following parameter restriction

$$
\sum_{j=1}^{J} \theta_{t}^{j} \frac{\gamma_{t}^{j}}{\Omega_{t} \gamma_{t}^{j}+1+\beta}>\frac{\lambda \bar{\gamma}_{t}}{\lambda \bar{\gamma}_{t} \Omega_{t}+\beta \Lambda_{t+1}}
$$

Consider next the case where the opposite of the above parameter restriction holds. In this case $\mathcal{E}_{t}+\mathcal{F}_{t}>0$, implying $\tau_{t}>0$ and at least some regional tax rates equal zero. In the sub-case where all regional tax rates equal zero, $\tau_{t}^{j}=0 \forall j$, the first-order condition for $\tau_{t}$ can be written as

$$
\bar{\gamma}_{t} \frac{(1+\lambda) \Omega_{t}}{\tau_{t}+(\sigma-1) x_{t}}=\frac{1+\beta+\beta \Lambda_{t+1}}{1-\tau_{t}} .
$$

Regional tax rates are in a corner if

$$
\frac{\Omega_{t} \gamma_{t}^{j}}{1+\beta}<\frac{\tau_{t}+(\sigma-1) x_{t}}{1-\tau_{t}} \forall j
$$

The sub-case in question therefore requires that

$$
\frac{\max _{j \in J} \gamma_{t}^{j}}{\bar{\gamma}_{t}}<\frac{(1+\beta)(1+\lambda)}{1+\beta+\beta \Lambda_{t+1}}
$$

The uniqueness result for the $J+1$ tax rates follows from the fact that the conditions characterizing tax rates include $r$ equalities and $J+1-r$ strict inequalities where $r \leq J$ denotes the number of interior tax rates.

\section{Proof of Proposition 3}

Suppose that all regional tax rates are interior such that

$$
\tau_{t}^{j}=\frac{\left(1-\tau_{t}\right) \delta \gamma_{t}^{j} \Omega_{t}-(1+\beta) \sigma x_{t}}{1+\beta+\delta \gamma_{t}^{j} \Omega_{t}} \forall j
$$

This implies $\bar{\varphi}_{t}=(1+\beta)\left(1-\tau_{t}+\sigma x_{t}\right) \sum_{j} \theta_{t}^{j} /\left(1+\beta+\delta \gamma_{t}^{j} \Omega_{t}\right)$ and $\sum_{j} \theta_{t}^{j} / \varphi_{t}^{j}=(1+\beta+$ $\left.\delta \bar{\gamma}_{t} \Omega_{t}\right) /\left[(1+\beta)\left(1-\tau_{t}+\sigma x_{t}\right)\right]$. 
With an interior federal tax rate the corresponding first-order condition holds with equality. Substituting the expressions above into this first-order condition yields

$$
\frac{\Omega_{t}(1-\delta)(1+\lambda) \bar{\gamma}_{t}}{\tau_{t}-x_{t}}=\frac{1+\beta+\delta \Omega_{t} \bar{\gamma}_{t}+\frac{\beta}{1+\beta} \Lambda_{t+1}\left(\sum_{j} \frac{\theta_{t}^{j}}{1+\beta+\delta \gamma_{t}^{j} \Omega_{t}}\right)^{-1}}{1-\tau_{t}+\sigma x_{t}} .
$$

Similarly, substituting the expressions above into the equilibrium condition for grants yields

$$
\frac{\sigma}{\Omega_{t}} \frac{1+\beta+\delta \Omega_{t} \bar{\gamma}_{t}+\lambda \bar{\gamma}_{t} \sum_{j} \frac{\theta_{t}^{j}\left(1+\beta+\delta \gamma_{t}^{j} \Omega_{t}\right)}{\gamma_{t}^{j}}}{1-\tau_{t}+\sigma x_{t}} \leq \frac{(1+\lambda)(1-\delta) \bar{\gamma}_{t}}{\tau_{t}-x_{t}} .
$$

Combining the last two relations, we conclude that interior tax rates constitute an equilibrium if the following inequality on parameters is satisfied:

$$
\begin{array}{r}
1+\beta+\delta \Omega_{t} \bar{\gamma}_{t}+\frac{\beta}{1+\beta} \Lambda_{t+1}\left(\sum_{j} \frac{\theta_{t}^{j}}{1+\beta+\delta \gamma_{t}^{j} \Omega_{t}}\right)^{-1} \geq \\
\sigma\left(1+\beta+\delta \Omega_{t} \bar{\gamma}_{t}+\lambda \bar{\gamma}_{t} \sum_{j} \frac{\theta_{t}^{j}\left(1+\beta+\delta \gamma_{t}^{j} \Omega_{t}\right)}{\gamma_{t}^{j}}\right) .
\end{array}
$$

Only in the non-generic case in which (10) holds with an equality then positive tax rates do constitute an equilibrium and grants are indeterminate. If it holds strictly then the marginal benefit of grants is negative; positive tax rates do constitute an equilibrium as well in this case and grants equal zero.

When $\gamma_{t}^{j}=\gamma_{t} \forall j$, this condition simplifies to

$$
1+\Lambda_{t+1} \frac{\beta}{1+\beta} \geq \sigma(1+\lambda)
$$

Intuitively, high deadweight losses of grants (small $\sigma$ ) or high indirect, general equilibrium costs of taxation (large $\Lambda_{t+1}$ ) render it more likely to observe no grants and thus, strictly positive taxes in all regions.

In the presence of heterogeneity, the cross-regional variance of the preferences for public services also affects the condition. A mean preserving spread of the $\gamma_{t}^{j}$ 's reduces the left hand side in (10) and increases the right hand side, thus making grants more likely. 


\section{Matching Grants}

With matching grants and perfect substitutability the first order conditions are given by

$$
\begin{array}{r}
\left(\frac{\omega}{\nu_{t}}+1\right) \frac{\gamma_{t}^{j}\left(1+\sigma x_{t}\right)}{\tau_{t}^{j}\left(1+\sigma x_{t}\right)+\tau_{t}-x_{t} \bar{\tau}_{t}}-\frac{1+\beta}{\varphi_{t}^{j}} \leq 0, \\
\sum_{j} \theta_{t}^{j}\left\{\left(\frac{\omega}{\nu_{t}}+1\right) \frac{\gamma_{t}^{j}}{\tau_{t}^{j}\left(1+\sigma x_{t}\right)+\tau_{t}-x_{t} \bar{\tau}_{t}}-\frac{1+\beta}{\varphi_{t}^{j}}\right\}+\mathcal{E}_{t}+\mathcal{F}_{t} \leq 0, \\
\sum_{j} \theta_{t}^{j} \frac{\left(\sigma \tau_{t}^{j}-\bar{\tau}_{t}\right) \gamma_{t}^{j}}{\tau_{t}^{j}\left(1+\sigma x_{t}\right)+\tau_{t}-x_{t} \bar{\tau}_{t}}+\frac{\lambda(\sigma-1) \bar{\tau}_{t} \bar{\gamma}_{t}}{\bar{\tau}_{t}\left(1+(\sigma-1) x_{t}\right)+\tau_{t}} \leq 0,
\end{array}
$$

where $\mathcal{E}_{t}=\lambda_{\overline{\bar{\tau}_{t}}\left(1+(\sigma-1) x_{t}\right)+\tau_{t}}$. When preferences are homogeneous and $\lambda=0$, the sign of $\mathcal{F}_{t}$ determines whether the national or regional governments tax, as in the case of uniform grants. Moreover, the first order condition for grants reduces to

$$
\frac{\gamma_{t}(\sigma-1) \tau_{t}^{j}}{\tau_{t}^{j}\left(1+(\sigma-1) x_{t}\right)+\tau_{t}} \leq 0
$$

implying that grants are not used if they entail deadweight losses. When $\sigma=1$ and $\mathcal{F}_{t}>0$ grants are irrelevant.

Consider next the case of heterogenous preferences, and possible non-zero $\lambda$. From the first order conditions it is straightforward that if $\mathcal{E}_{t}+\mathcal{F}_{t}<0$, the equilibrium features positive taxes in all regions, the federal government collects no revenue, and therefore grants are zero $\left(x_{t}=0\right)$. Thus, the restriction $\mathcal{E}_{t}+\mathcal{F}_{t}<0$ implies $\frac{\lambda \bar{\gamma}_{t} \Omega_{t}}{\bar{\tau}_{t}}-\frac{\beta}{1-\bar{\tau}_{t}} \Lambda_{t+1}<0$, and the following parameter restriction

$$
\sum_{j=1}^{J} \theta_{t}^{j} \frac{\gamma_{t}^{j}}{\Omega_{t} \gamma_{t}^{j}+1+\beta}>\frac{\lambda \bar{\gamma}_{t}}{\lambda \bar{\gamma}_{t} \Omega_{t}+\beta \Lambda_{t+1}}
$$

This is the same condition that we found in appendix $\mathrm{C}$ for uniform grants. The main distinction with that case is that now it is not straightforward that the reverse of the condition above, namely $\mathcal{E}_{t}+\mathcal{F}_{t}>0$, implies that at least some regional tax rates are zero. The reason for this is that the first terms in the first order condition for $\tau_{t}$ will be strictly negative when all $\tau_{t}^{j}>0$ and $x_{t}>0$. Nevertheless, we can show that when there are no dead-weight losses, i.e. $\sigma=1$, grants are used and they must fully crowd out taxes in at least one region. To prove this, we start by assuming that all regional taxes are positive. From the regional first order condition we find

$$
\tau_{t}^{j}=\frac{\Omega_{t} \gamma_{t}^{j}\left(1+\sigma x_{t}\right)-\tau_{t}\left[1+\beta+\Omega_{t} \gamma_{t}^{j}\left(1+\sigma x_{t}\right)\right]+(1+\beta) x_{t} \bar{\tau}_{t}}{\left(1+\sigma x_{t}\right)\left[1+\beta+\Omega_{t} \gamma_{t}^{j}\right]},
$$

and thus,

$$
\tau_{t}^{j}\left(1+\sigma x_{t}\right)+\tau_{t}-x_{t} \bar{\tau}_{t}=\frac{\Omega_{t} \gamma_{t}^{j}\left[\left(1+\sigma x_{t}\right)-\sigma x_{t} \tau_{t}-x_{t} \bar{\tau}_{t}\right]}{1+\beta+\Omega_{t} \gamma_{t}^{j}} .
$$


Replacing in the first order condition for $x_{t}$ yields

$$
\frac{\sum_{j} \theta_{t}^{j}\left(\sigma \tau_{t}^{j}-\bar{\tau}_{t}\right)\left(1+\beta+\Omega_{t} \gamma_{t}^{j}\right)}{\Omega_{t}\left[1+\sigma x_{t}\left(1-\tau_{t}\right)-x_{t} \bar{\tau}_{t}\right]}+\frac{\lambda(\sigma-1) \bar{\tau}_{t} \bar{\gamma}_{t}}{\bar{\tau}_{t}\left(1+(\sigma-1) x_{t}\right)+\tau_{t}} \leq 0
$$

If $\sigma=1$ the left hand side reduces to

$$
\frac{1}{\left[1+x_{t}\left(1-\tau_{t}-\bar{\tau}_{t}\right)\right]} \sum_{j} \theta_{t}^{j}\left(\tau_{t}^{j}-\bar{\tau}_{t}\right) \gamma_{t}^{j}
$$

Since regional taxes are increasing in $\gamma_{t}^{j},(11)$ is strictly positive for all $x_{t} \geq 0$. Thus, the first order condition for grants is not satisfied if all regional tax rates are positive. We conclude that when $\mathcal{E}_{t}+\mathcal{F}_{t}>0$ such that $\tau_{t}>0$, and there are no dead-weight losses from grants, these will be used and they crowd out regional spending in at least one type of region, that with the lowest $\gamma_{t}^{j}$. By continuity the same reasoning holds when deadweight losses are positive but small. Finally, when there are deadweight losses, and $\mathcal{E}_{t}<0$, grants might be used to waste resources, as in the case with uniform grants.

With imperfect substitutability the first order conditions are given by

$$
\begin{array}{r}
\Omega_{t} \frac{\gamma_{t}^{j} \delta}{\tau_{t}^{j}}-\frac{1+\beta}{\varphi_{t}^{j}} \leq 0 \\
\sum_{j} \theta_{t}^{j}\left\{\Omega_{t} \frac{\gamma_{t}^{j}(1-\delta)}{\tau_{t}-x_{t} \bar{\tau}_{t}}-\frac{1+\beta}{\varphi_{t}^{j}}\right\}+\mathcal{E}_{t}+\mathcal{F}_{t} \leq 0 \\
\sigma \delta \frac{(1+\lambda) \bar{\gamma}_{t}}{1+\sigma x_{t}}-\frac{(1-\delta)(1+\lambda) \bar{\tau}_{t} \bar{\gamma}_{t}}{\tau_{t}-x_{t} \bar{\tau}_{t}} \leq 0
\end{array}
$$

With $\mathcal{E}_{t}=\lambda \Omega_{t} \sum_{j} \theta_{t}^{j} \frac{\gamma_{t}^{j}(1-\delta)}{\tau_{t}-x_{t} \bar{\tau}_{t}}$. Note that now all tax rates are interior, regardless of whether there are grants in place or not, and the grant rate does not directly affect the incentives for regional taxes.

There will be no grants when

$$
\delta \sigma-\frac{(1-\delta) \bar{\tau}_{t}}{\tau_{t}}<0
$$

From regional governments' first order conditions we get $\tau_{t}^{j}=\frac{\Omega_{t} \delta \gamma_{t}^{j}\left(1-\tau_{t}\right)}{1+\beta+\Omega_{t} \delta \gamma_{t}^{j}}$, and $\varphi_{t}^{j}=$ $\frac{(1+\beta)\left(1-\tau_{t}\right)}{1+\beta+\Omega_{t} \delta \gamma_{t}^{j}}$. Thus, we can calculate the following averages, and the factor price effect

$$
\begin{array}{r}
\sum_{j} \frac{\theta_{t}^{j}}{\varphi_{t}^{j}}=\frac{1+\beta+\Omega_{t} \delta \bar{\gamma}_{t}}{(1+\beta)\left(1-\tau_{t}\right)}, \\
\bar{\varphi}_{t}=(1+\beta)\left(1-\tau_{t}\right) \sum_{j} \frac{\theta_{t}^{j}}{1+\beta+\Omega_{t} \delta \gamma_{t}^{j}}, \\
\mathcal{F}_{t}=-\frac{\beta \Lambda_{t+1}}{(1+\beta)\left(1-\tau_{t}\right)} \frac{1}{\sum_{j} \frac{\theta_{t}^{j}}{1+\beta+\Omega_{t} \delta \gamma_{t}^{j}}} .
\end{array}
$$


Using the above expressions to solve for $\tau_{t}$ and $\bar{\tau}_{t}$ (assuming $x_{t}=0$ ) we get

$$
\begin{array}{r}
\tau_{t}=\frac{(1-\delta)(1+\lambda) \Omega_{t} \bar{\gamma}_{t}}{\Omega_{t} \bar{\gamma}_{t}[\delta+(1+\lambda)(1-\delta)]+1+\beta+\frac{\beta}{1+\beta} \frac{\Lambda_{t+1}}{\sum_{j} \frac{\theta_{t}^{j}}{1+\beta+\Omega_{t} \delta \gamma_{t}^{j}}}}, \\
\bar{\tau}_{t}=\left(1-\tau_{t}\right) \Omega_{t} \delta \sum_{j} \frac{\theta_{t}^{j} \gamma_{t}^{j}}{1+\beta+\Omega_{t} \delta \gamma_{t}^{j}} .
\end{array}
$$

Replacing in (12) we have that grants will not be used if

$$
\sigma(1+\lambda) \bar{\gamma}_{t}<\sum_{j} \frac{\theta_{t}^{j} \gamma_{t}^{j}}{1+\beta+\Omega_{t} \delta \gamma_{t}^{j}}\left(\Omega_{t} \bar{\gamma}_{t} \delta+1+\beta+\frac{\beta}{1+\beta} \frac{\Lambda_{t+1}}{\sum_{j} \frac{\theta_{t}^{j}}{1+\beta+\Omega_{t} \delta \gamma_{t}^{j}}}\right) .
$$

To gain intuition we now consider the special case of homogeneous preferences. Grants would not be used if

$$
\sigma(1+\lambda)<1+\frac{\beta}{1+\beta} \Lambda_{t+1}
$$

This is the same condition that we found for the case of uniform grants. 


\section{References}

Alesina, A. and Spolaore, E. (1997), 'On the number and size of nations', Quarterly Journal of Economics 112(4), 1027-1056.

Ansolabehere, S., Rodden, J. and Snyder Jr., J. M. (2006), 'Purple America', Journal of Economic Perspectives 20(2), 97-118.

Besley, T. and Coate, S. (2003), 'Centralized versus decentralized provision of local public goods: A political economy approach', Journal of Public Economics 87(12), 26112637.

Boffa, F., Piolatto, A. and Ponzetto, G. A. M. (2016), 'Political centralization and government accountability', Quarterly Journal of Economics 131(1), 381-422.

Bolton, P. and Roland, G. (1997), 'The breakup of nations: A political economy analysis', Quarterly Journal of Economics 112(4), 1057-1090.

Dales, S. R. (1970), 'Federal grants to state and local governments 1968-1969', Social Security Bulletin 33, 31-38.

Dales, S. R. (1971), 'Federal grants to state and local governments 1969-1970', Social Security Bulletin 34, 15-23.

Frank, T. (2004), What's the Matter with Kansas?, Henry Holt, New York.

Gonzalez-Eiras, M. and Niepelt, D. (2008), 'The future of social security', Journal of Monetary Economics 55(2), 197-218.

Gordon, R. H. (1983), 'An optimal taxation approach to fiscal federalism', Quarterly Journal of Economics 98(4), 567-586.

Gruber, J. (2011), Public Finance and Public Policy, 3rd edn, Worth, New York.

Harstad, B. (2007), 'Harmonization and side payments in political cooperation', American Economic Review 97(3), 871-889.

Kessler, A. S. (2014), 'Communication in federal politics: Universalism, policy uniformity, and the optimal allocation of fiscal authority', Journal of Political Economy 122(4), 766-805.

Kincaid, J., ed. (2011), Federalism, Sage Publications, Los Angeles.

Knight, B. (2002), 'Endogenous federal grants and crowd-out of state government spending: Theory and evidence from the federal highway aid program', American Economic Review 92(1), 71-92.

Kotlikoff, L. J. and Rosenthal, R. W. (1990), Some inefficiency implications of generational politics and exchange, Working Paper 3354, NBER, Cambridge, Massachusetts. 
Krusell, P., Quadrini, V. and Ríos-Rull, J.-V. (1997), 'Politico-economic equilibrium and economic growth', Journal of Economic Dynamics and Control 21(1), 243-272.

Lindbeck, A. and Weibull, J. W. (1987), 'Balanced-budget redistribution as the outcome of political competition', Public Choice 52, 273-297.

Lockwood, B. (2002), 'Distributive politics and the costs of centralization', Review of Economic Studies 69(2), 313-337.

Oates, W. E. (1972), Fiscal Federalism, Harcourt Brace Jovanovich, New York.

Oates, W. E. (1999), 'An essay on fiscal federalism', Journal of Economic Literature $37(3), 1120-1149$.

Persson, T. and Tabellini, G. (1996), 'Federal fiscal constitutions: Risk sharing and redistribution', Journal of Political Economy 104(5), 979-1009.

Persson, T. and Tabellini, G. (2000), Political Economics, MIT Press, Cambridge, Massachusetts.

Piketty, T. and Saez, E. (2003), 'Income inequality in the United States, 1913-1998', Quarterly Journal of Economics 118(1), 1-39.

Seabright, P. (1996), 'Accountability and decentralisation in government: An incomplete contracts model', European Economic Review 40(1), 61-89.

Soares, J. (2005), 'Public education reform: Community or national funding of education?', Journal of Monetary Economics 52(3), 669-697.

Song, Z., Storesletten, K. and Zilibotti, F. (2012), 'Rotten parents and disciplined children: A politico-economic theory of public expenditure and debt', Econometrica 80(6), 2785-2803.

Treisman, D. (2007), The Architecture of Government, Cambridge University Press, Cambridge.

Wallis, J. J. (2000), 'American government finance in the long run: 1790 to 1990', Journal of Economic Perspectives 14(1), 61-82. 